\title{
The Duration of Bank Retail Interest Rates
}

\section{Ben R. Craig and Valeriya Dinger}

Working Paper 88

November 2011

\section{INSTITUT FÜR EMPIRISCHE WIRTSCHAFTSFORSCHUNG \\ University of Osnabrueck \\ Rolandstrasse 8 \\ 49069 Osnabrück \\ Germany}


The Duration of Bank Retail Interest Rates

Ben R. Craig* and Valeriya Dinger**

\begin{abstract}
We use bank retail interest rates as price examples in a study of the determinants of price durations. The extraordinary richness of the data allows us to address some major open issues from the price rigidity literature, such as the functional form of the hazard of changing a price, the effect of firm and market characteristics on the duration of prices, and asymmetry in the speed of adjustments to positive and negative cost shocks. We find that the probability of a bank changing its retail rate initially (that is, in roughly the first six months of a spell) increases with time. The most important determinants of the duration of retail interest rates are the cumulated change in the money market interest rates and the policy rate since the last retail rate change. Among bank and market characteristics, the size of the bank, its market share in a given local market, and its geographical scope significantly modify retail rate durations. Retail rates adjust asymmetrically to positive and negative wholesale interest rate changes; the asymmetry of the adjustment is reinforced in part by the bank's market share. This suggests that monopolistic distortions play a vital role in explaining asymmetric price adjustments.
\end{abstract}

Key words: price stickiness, interest rate pass-through, duration analysis, hazard rate

We thank Antonio Antunes, Christian Bayer, Diana Bonfim, Tim Dunne, Eduardo Engel, Roy Gardner, James Thomson, Jürgen von Hagen, and participants of the University of Bonn MacroWorkshop, Banco de Portugal Research Seminar, and the 2010 European Economic Association meetings for useful comments on earlier versions, and Monica Crabtree-Reusser for editorial assistance. Dinger gratefully acknowledges financial support by the Deutsche Forschungsgemeinschaft (Research Grant DI 1426/2-1). This research reflects the views of the authors and not necessarily the views of the Deutsche Bundesbank, the Federal Reserve Bank of Cleveland, or the Board of Governors of the Federal Reserve System.

\footnotetext{
* Federal Reserve Bank of Cleveland and Deutsche Bundesbank

** Corresponding author. University of Osnabrueck, Rolandstr. 8, 49069 Osnabrueck, Germany, Tel: +49 5419693398, Fax: +49 5419692769, e-mail: valeriya.dinger@uni-osnabrueck.de.
} 


\section{Introduction}

Price inflexibility is a key determinant of business cycle fluctuations and the efficiency of monetary policy. Theoretical work has proposed alternative views on the sources of this inflexibility, ranging from pure time dependency (Calvo 1983; Taylor 1980) and information costs (Mankiw and Rice 2002) to state-dependent adjustment costs (Sheshinski and Weiss 1977; Caplan and Spulber 1987) as well as a combination of information and adjustment costs (Alvarez et al 2010). Modern empirical research has focused on evaluating the validity of these models, mainly using pricing data for broad range of product categories (e.g. CPI, scanner or scraped data) ${ }^{1}$. These studies have substantially improved the profession's understanding of factors that affect the duration of price spells. Nevertheless, data limitations associated with the multiproduct dimensions of the data have constrained the ability of these macroeconomic studies to resolve some ambiguities. In particular, (i) empirical estimation of the functional form of the hazard of price changes, which is typically used to discriminate among alternative theoretical models, produces results inconsistent with any of the suggested models; (ii) the empirical relation between firm and market characteristics and price-spell duration has still not been identified; and (iii) the sources of the asymmetric adjustment to positive and negative cost shocks are not well understood.

Earlier empirical research has found downward-sloping hazards (Nakamura and Steinsson, 2009; Alvarez, Burriel, and Hernando, 2005). This result is inconsistent with most pricesetting theories, which suggest flat or upward-sloping hazards. The empirically documented downward-sloping hazards are usually explained by product heterogeneity ${ }^{2}$. In addition, economic theory has so far suggested monopolistic distortions and asymmetric adjustment costs as possible sources of an asymmetry of downward and upward price adjustments, but empirical research has failed to find convincing support for any of these factors (see Petzman, 2000; Hannan, 1994).

\footnotetext{
${ }^{1}$ Seminal examples include Bils and Klenow 2004, Nakamura and Steinsson 2009

${ }^{2}$ The importance of exploring heterogeneity is underlined by a recent study focused on scraped data by Cavallo (2011) which finds hump-shaped hazards of individual product prices in a few Latin American economies.
} 
A potential explanation for both puzzles is that although theories have been designed to address price dynamics at the micro (firm-product) level, empirical tests are usually based on more aggregate, cross-industry comparisons (Bills and Klenow, 2004; Nakamura and Svensson, 2009). The major shortcomings of cross-industry comparisons are that they cannot identify the impact of unobserved, industry-specific factors, they cannot control for firm- and industry-specific characteristics, and they cannot deal with industry-level product heterogeneity. A newer strand of the price-rigidity literature, involving scanner data from one or a few retail firms (Eichenbaum and Jaimovich, forthcoming; Burstein and Hellwig, 2007) helps address product heterogeneity. But since the scope of scanner data is limited to one or a few firms, these studies cannot yet address the impact of firm and industry variation on the form of the hazard and on the asymmetry of price adjustment. Moreover, the limited scope of both industry-level and scanner data limits the potential usefulness of both sets of data in analyzing the effects of firm- and market-specific variables on price durations.

In this paper, we revisit the issue of the infrequency of price changes, using a new, comprehensive dataset that allows us to address the three open questions mentioned earlier. For price examples, we use the data explore the retail interest rates offered by roughly 600 U.S. banks in about 160 local markets. While the focus on the "pricing" of just a few retail "products" admittedly limits the scope of the analyzed pricing behavior, it allows us to perform deeper microeconometric exploration of the determinants of the pricing behavior for the analyzed product categories. The main advantage of using retail interest rates in this framework is the extraordinary data availability that allows us to combine high-frequency information on the retail interest rates offered by a large sample of U.S. commercial banks in different local markets (defined as metropolitan statistical areas, or MSAs) with information on the key features of the offering banks and their respective local markets. As a result, we can observe the price-changing behavior of many multiproduct, multimarket firms while also knowing the firm and market characteristics. 
The empirical analysis is structured around testing the theoretical hypothesis of statedependent pricing based on the assumption that the decision to change a price is determined by the trade-off between the costs of deviation from an unobservable optimal price level and the costs of adjusting the price to this optimal level (Sheshinski and Weiss, 1977; Caplan and Spulber, 1987; Caballero and Engel, 2007). We can approximate changes in the optimal interest rate, which are otherwise unobservable, by tracking the dynamics of market and monetary policy interest rates. We control for additional factors that could affect both the optimal price level and the adjustment costs by including bank-specific and market-structure variables, such as the bank's size, its market share and geographical scope, and the concentration of the market.

Our approach benefits from a few features of using the retail-interest-rate setting as a laboratory for exploring price dynamics. To start with, the approximation of optimal price changes is less controversial than in other industries, where the cost and revenue structures are usually less transparent. Moreover, the fact that bank retail products are relatively homogeneous alleviates heterogeneity concerns in analyzing the form of the hazard function, and the fact that interest rate dynamics are typically studied in the longer term, characterized by both downward and upward movements, enriches our ability to address the issues of asymmetry of adjustment. In our view, these advantages outweigh the difficulties associated with the role of bank-customer relationships in interest rate setting and the link between loan interest rates and borrowers' risk, which we nevertheless discuss in detail.

Our analysis of retail interest rate durations proceeds as follows: We start by summarizing the descriptive statistics of micro-level retail interest rate dynamics. We show that retail interest rate changes for a broad set of retail bank products are very infrequent and are large when they do occur (much larger than the average price change for goods and services). We then study the duration of the periods ("spells") over which retail interest rates remain fixed. We find that the duration varies substantially both within and across bank products. To shed more 
light on this variation, we employ duration analysis to study the form of the hazard of changing bank retail rates as well as the hazard's determinants.

The nonparametric estimation of the hazard function's form uncovers a hump-shaped relationship between the time since the latest change in the retail rate and the probability that the retail rate will be changed. This form of the estimated hazard function suggests that the conditional probability of a rate change increases within the first five to seven months after a change and decreases afterwards. The hump-shaped hazard is an interesting observation in view of the existing literature, which so far has generally found downward-sloping hazards ${ }^{3}$. It indicates that, consistent with state-dependant theories, concentrating on relatively homogenous sets of products generates the initially upward-sloping hazard. However, the downward-sloping hazard, after the local maximum is reached at roughly six months, might still arise due to heterogeneity across bank pricing strategies. (If we have a set of banks that re-price very frequently and some that re-price very infrequently, after a few periods we will be left with the long spells of infrequently adjusting banks, and the form of the hazard function will slope downward.)

The infrequency and the large magnitude of the interest rate changes as well as the initially increasing form of the hazard function are all consistent with state-dependent "price"-setting behavior. We scrutinize the exploration of the state-dependency of retail rate changes by analyzing the determinants of the spells' duration. For this purpose we construct empirical proxies for the magnitude of the deviation of the current retail rate from the unobserved “optimal" rate. These proxies not only account for the general interest rate dynamics but also allow for heterogeneity across retail responses to aggregate interest rate dynamics based on the variation of bank and market characteristics. Estimating a semi-parametric COX proportional hazard duration model, we find support for state-dependent pricing behavior reflected in the economically and statistically strongly significant impact of general interest

\footnotetext{
${ }^{3}$ We are aware of a study by Cavallo (2011), which also finds hump-shaped hazards using individual product-level scraped data from four Latin American economies.
} 
rate dynamics. The response to wholesale rate changes is also strongly asymmetric: A drop in the wholesale rate accelerates a bank's decision to change deposit rates, while a rise in the wholesale rate does not accelerate the re-pricing decision. The converse is true for loan rates. The response to wholesale rate changes also strongly depends on bank and market characteristics, suggesting consistent with classical industrial organization theory that the reaction of the optimal retail rate to wholesale rate dynamics is modified by the banks' market position.

With regard to the asymmetry in price dynamics, we not only confirm the results suggested by earlier papers that were based on more restrictive methodologies (Berger and Hannan, 1991; Neumark and Sharpe, 1992; Petzman, 2000) but also take the advantage of our rich dataset to revisit the topic of asymmetric price adjustment by employing competing risks duration models that analyze positive and negative retail interest rate changes as separate failure events. The benefits of the competing risks model can be summarized in two ways. First, we can explore the effect of covariates that increase the risk of increasing and decrease the risk of decreasing retail rates (or vice versa). Since these effects offset one another, their effect cannot be correctly tracked in a standard hazard rates model. To that end, we estimate separately the effect of positive and negative interest rate changes on the hazards of positive and negative retail rate changes. We also add bank and market characteristics as covariates in the competing risks models to explore their potential effect on reinforcing asymmetry. The results of the estimation indicate that the effect of interest rate dynamics is indeed partially offset in a classical hazard model. They also uncover the bank's market share as the main factor reinforcing the asymmetry of adjustment.

Besides the previously discussed contributions to the price rigidity literature with regard to the form of the hazard, the identification of firm- and market-specific effects, and the asymmetry of the adjustment, our results also contribute to the literature of interest rate dynamics. So far, this literature has focused either on the probability of a bank keeping its retail interest rates 
unchanged for a certain exogenously chosen period of time (Berger and Hannan, 1991; Neumark and Sharpe, 1992; and Mester and Sounders, 1995) or on the incompleteness of retail interest rate adjustments to changes in monetary policy (see Hofmann and Mizen, 2004; de Graeve et al., 2007; Kleimeier and Sander, 2006; and others). The major disadvantage of the former is that its focus on exogenously given time periods (usually a month or a quarter) ignores the short- and long-term dynamics of retail interest rates. The latter strand of the literature is challenged by the fact that it uses techniques, such as vector-autoregression analysis, that were originally designed for use with the time series of aggregate data. The smooth adjustment assumptions are too strong when imposed on micro-level data, so the robustness of the results is not guaranteed. In particular, the linearity of cointegration implies a quadratic cost of adjusting the interest rate. ${ }^{4}$ We contribute to the literature on interest rate dynamics by confirming its key micro-level results of asymmetrically delayed adjustment of retail rates to monetary policy rate changes, using the less restrictive framework of the duration analysis. Unlike the cointegration approach currently used to study interest rate dynamics, the use of the hazard functions involved in duration analysis implies less strict assumptions about the time series properties of the adjustment process; thus, it is closer to a structural approach. The duration analysis also allows us to include more control variables than we could within a cointegration framework that allow us to address more precisely the role of market structure for retail interest rate dynamics. By documenting the effect of market structure characteristics as determinants of firms' (banks') price changing decision, our results also contribute to the industrial organization literature. Research in this area has so far been concerned with single products in a limited number of markets (for example, see Slade, 1998, an analysis of a price changing decision for saltine crackers; and Nakamura and Zerom, 2010 for the case of retail coffee price changes). Taking advantage of an extraordinarily rich dataset, we extend the scope of this strand of the literature by exploring the effects of

\footnotetext{
${ }^{4}$ Hofmann and Mizen (2004) and De Graeve et al. (2007) relax the linear cointegration assumption and estimate nonlinear error-correction models as robustness checks. These still assume continuous adjustment, which is inconsistent with menu cost models.
} 
numerous firm and market characteristics that are used as proxies for industrial structure and comparing these effects across different products in a joint empirical framework.

The rest of the paper is structured as follows: In section 2, we describe the frequency and duration of retail deposit and loan rate spells. In section 3, we use hazard functions to analyze the duration of individual price spells, focusing in particular on the impact of wholesale rate changes on the probability that retail interest rates will change, bringing a spell to an end, and how this reaction is modified by bank and local market characteristics. Section 4 employs competing risk models to study the determinants of asymmetric adjustments. Section 5 concludes.

\section{Empirical Framework}

\section{a. Data}

Our dataset contains the deposit rates of 624 U.S. banks in 164 local markets ${ }^{5}$ (a total of 1,738 bank-market groups) and the loan rates of 86 U.S. banks in 10 local markets (a total of 254 bank-market groups) for the period starting September 19, 1997, and ending July 21, 2006. These rates are obtained from Bank Rate Monitor. Our deposit rate data comprise by far the largest sample that has yet been employed to study the price dynamics of homogenous products. The loan rate data sample available to us is much smaller (though we are not aware of any studies using larger ones). It includes only rates offered by the largest U.S. banks in the 10 largest banking markets (the MSAs of Boston, Chicago, Dallas, Detroit, Houston, Los Angeles, New York, Philadelphia, San Francisco, and Washington, D.C.). Because of the small sample size and the fact that only the largest banks in the largest markets are covered, bank and local market characteristics are likely to vary much less in our loan rate data than in our deposit rate sample.

The time span of our data is the longest employed so far in a study of retail interest rate dynamics. The period encompasses a full interest rate cycle. The Federal Reserve target rate

\footnotetext{
${ }^{5}$ Local markets are defined, in the tradition of the banking literature, as metropolitan statistical areas (MSAs).
} 
moved from 5.5 percent at the beginning of the sample period down to 1 percent in 2003 , then back up to 5.25 percent towards the end of the period. During the observed time, there were 25 positive and 17 negative changes in the federal funds target rate. The substantial upward and downward changes in the fed funds rate allow us to study the connection between retail and wholesale rate dynamics during a period with substantial wholesale rate variation.

Bank Rate Monitor reports a comprehensive set of retail deposit products (checking accounts, money market deposit accounts, and certificates of deposit with maturities of three months to five years) and retail loan products (personal loans, fixed- and variable-rate credit cards, mortgages, home equity lines of credit, auto loans, etc.). Note that rates for these products are offered to customers with the best credit rating and with no other relation to the bank. Rates on products offered to existing customers might vary from those reported by Bank Rate Monitor. The rates reported by BankRate Monitor should be viewed as posted reference rates. Even though actual transactions could take place at a different rate, a change in the reported rate reflects a change in the reference rate around which the pricing policy is organized.

Interest rates for each product are given at a weekly frequency. The availability of weekly data allows us to differentiate more precisely the speed of adjustment compared to previous studies of interest rate rigidity (Berger and Hannan, 1991; and Neumark and Sharpe, 1992) and price rigidity (Bils and Klenow, 2004; and Nakamura and Steinsson, 2008), which use data at monthly or bimonthly frequencies. ${ }^{6}$

We enrich the dataset with a broad range of control variables for individual banks, taken from the Quarterly Reports of Conditions and Income (Call Reports). We also include MSA market level characteristics that are taken from the Summary of Deposits and are only available at an annual frequency (the reporting date is June 30).

\footnotetext{
${ }^{6}$ To our knowledge, studies based on scanner data are the only ones with frequencies that are higher than monthly. However, they use data from only a single retailer, although possibly in different markets (Eichenbaum, Jaimovich, and Rebello, forthcoming).
} 
We observe substantial variation in the deposit and loan rates offered by multimarket banks in different MSAs and therefore use the bank market as the pricing unit and use the variation among multimarket bank rates across local markets to identify the effect of market structure on interest rate dynamics. ${ }^{7}$

\section{b. Spells}

We set up the analysis of retail interest rate durations by defining an interest rate spell and individual quote lines. We define the quote line $\mathrm{i}_{\mathrm{i}, \mathrm{p}}$ as the set of interest rates offered by bank $i$ in local market $j$ for (deposit or loan) product $p$. The interest rate spell is defined as a subsection of the quote line for which the interest rate goes unchanged. This definition assumes that if the same interest rate is reported in two consecutive weeks, it has not changed between observations. We define the number of weeks during which the interest rate goes unchanged as the duration of the interest rate spell.

To avoid left and right censoring, we include only spells for which we can identify the exact starting and ending dates (the week for which a particular rate was offered for the first time and the last time). A spell ends with either a change in the interest rate or the exit of the bankmarket unit from the observed sample. Identification of the ending date is complicated by the fact that Bank Rate Monitor reports rates offered by smaller banks only if the quoted rate deviates from the one quoted the preceding week. To control for this, we assume that an interest rate spell "survives" through the weeks until the next observation is reported. (If the next reported rate is in week $t$, we assume the rate has "survived" until week $t-1$ ). However, in the few instances in our sample in which the bank-market unit exits the sample for a longer period (up two a few years) and re-enters the sample, the assumption that observations are missing only because there was no change in the interest rate is too strong. We control for this

\footnotetext{
${ }^{7}$ An estimation bias can arise if a bank-specific pricing effect impacts pricing behavior in all local markets, where the assumption of spherical standard errors can no longer be sustained. We account for potential bankspecific effects by estimating hazard functions using a shared frailty technique (see Nakamura and Steinsson, 2008, which applies a similar approach to control for heterogeneity across product groups).
} 
by treating an unreported rate as an unchanged rate only if the period of missing observations is less than 52 weeks. ${ }^{8}$

\section{c. Descriptive statistics and key facts about retail interest rate changes}

The average duration and the average change in the retail rates for each of the deposit and loan product categories are presented in Table 1. The data illustrate a substantial variation in the average duration of interest rates across different bank products, with checking account rates and money market deposit account rates being the most inflexible deposit rates, ${ }^{9}$ and personal loan and credit card rates being the most inflexible consumer loan rates. The average duration of checking account rates is 17.71 weeks (roughly four months). Similarly, money market deposit account rates, personal loan rates, and fixed credit card rates change roughly every three months on average.

Not only do the data show that interest rate changes are infrequent, but they also suggests that the average retail interest rate change is very large. The second column of Table 1 presents the average absolute value of the interest rate change, given a nonzero rate change. This average change is more informative when put into relation with the average value of the respective interest rate (for example, the average change in the checking account rate seems very low in absolute value, 0.16 , but this represents roughly a third of the average checking account rate). The fourth column of Table 1 presents the average absolute value of the changes relative to the average rates. For checking account rates, the average size of the interest rate change is 30 percent. This average rate change is much higher than the average price change documented for any good or service categories (see Nakamura and Steinsson, 2008, who find that the highest average magnitude of regular price changes across all product groups is 21.6 percent—for the product group “travel”). Similarly, the average size of money market deposit

\footnotetext{
${ }^{8}$ We did a few robustness checks here. For example, for the checking account rates, our approach identifies 204 spells when the rate was not observed for a few weeks but reappeared with a changed value within 52 weeks. If we account only for rates that reappear within 26 weeks, we can identify 191 spells. If we impose no cut-off point with regard to the number of weeks a price was not observed, we have a total of 311 spells.

${ }^{9}$ The same has been found in the interest rate pass-through literature (see de Graeve et al., 2007).
} 
account rate changes is also very high (24 percent). The average size of loan rate adjustments is likewise relatively high (12 percent). The combination of infrequent and large retail interest rate changes indicates a lumpy adjustment process, which is consistent with theories of price adjustment in the presence of non-convex adjustment costs.

In the rest of the paper we focus on the timing of the rate change of the most inflexible deposit and loan rates: the checking account, the MMDA, the personal loan and the fixed credit card rate. The focus on these products which show degrees of "price" inflexibility very much comparable to those of average product groups studied using CPI data (see Bils and Klenow 2004; Nakamura and Steinsson 2009) is related to our goal to use retail interest rates as a laboratory for the examination of price inflexibility. The two deposit products we focus on are the most widely offered retail deposit product. Checking accounts represent on average around $10 \%$ and MMDAs around $15 \%$ in the sample banks' liabilities. Personal loans and fixed rate credit card lending represents a smaller portion of bank liabilities, but are of crucial importance for funding retail customers' consumption. It is likely that credit card contracts are offered to new customers with teaser rates ${ }^{10}$. This would, however, suggest that the credit card rates published by BankRate Monitor - being teaser rates on new contracts- are less rigid and asymmetric than the rates actually prevailing in the market. In this case, our results on both the inflexibility of fixed credit card rates and the asymmetry of adjustment would even be reinforced. Note that the average duration and change in the rates, presented in Table 1, reflect all interest rate changes observed in the data. Next, we account for the treatment of temporary interest rate changes as an analogue of temporary price changes (sales), which represent an important measurement issue and are considered an important link in the chain of the price-setting mechanism (Bills and Klenow, 2004; Nakamura and Steinsson, 2008). ${ }^{11}$

\footnotetext{
${ }^{10}$ See for example Calem, Gordy and Mester 2006.

${ }^{11}$ With regard to interest rate setting, the issue of temporary interest rate changes is more subtle. Whereas a change in the price of goods and services that is reversed after a few periods is usually classified as a sale, such automatic labelling is more controversial when applied to interest rates. To illustrate this subtlety, consider the case in which a bank has been slow to adjust its retail rates to an upward trend in wholesale rates, and it raises its retail rates only shortly before wholesale rates start declining. In this case, the reversion of the retail interest rate to its previous level can simply reflect a reaction to changes in the wholesale rate rather than a "sale." Note that
} 
Table 2 illustrates the number of temporary interest rate changes for some deposit and loan products. ${ }^{12}$ These could be considered "sales" in the classical price-dynamic sense, but could as well represent pure measurement errors. Note that the proportion of price spells that reversed after a week is particularly high. It suggests that we might be dealing with measurement errors that result from misreporting the rate in a particular week, rather than a de facto change in the interest rate. To account for this, in the rest of this section we will track the duration of spells, both including and excluding temporary interest rate changes.

The distribution of the duration of spells for checking account and money market deposit account rates and personal loan and fixed credit card rates is presented in Chart 1-Chart 4. The distributions uncover the heterogeneity of the duration of interest rate spells within each deposit and loan product category. Most types of interest rates shown in these charts have spell durations of less than year. However, for both deposit and loan rates a substantial portion of the spells last for two years and even longer. For example, if we focus on the second panel of the distribution charts (which does not treat rates reversed in one week as spell-ending), 237 out of 7,456 spells of checking account rate spells last for more than 104 weeks. These are offered by 78 different banks. In the case of money market deposit account rates, 197 out of 12,833 spells survive for more than two years. These are offered by 76 banks. For personal loan rates, only 8 spells out of 663 last for more than two years, and these are offered by 8 different banks.

Finally, 7 fixed credit card rate spells (out of 630) last longer than two years, and these are offered by 7 different banks. Note that whereas some banks repeatedly offer very rigid rates for deposit accounts, this is not the case for loan rates. This difference could result from our sample sizes. Although the sample of banks for which we have deposit rates is relatively

\footnotetext{
because interest rate values are often rounded at 25 basis points, there is a high probability of returning to exactly the same interest rate after a reversal in the level of the aggregate interest rate trend. Therefore, it might be misleading to call any interest rate change that is reversed after a few weeks a "sale."

${ }^{12}$ Table 2 only reflects the interest rate changes that are reversed in four weeks or less. The number of changes reversed within five, six, seven, and eight weeks is substantially lower, and we treat these as regular price changes (implying the end of an interest rate spell).
} 
comprehensive, it is limited to the biggest banks in the case of loan rate data, and these banks are certainly less heterogeneous than others.

We can summarize the descriptive statistics presented in this section with three key facts about retail interest rate dynamics. First, the variation of the mean duration of interest rates across different deposit and loan products is very high. While rates on certificates of deposits and mortgages change frequently, rates on purely retail service products, such as checking accounts, money market deposit accounts, personal loans, and credit cards, are quite inflexible. The rest of this paper focuses on the dynamics of these less flexible deposit and loan rates. ${ }^{13}$

Second, there is great variation in the duration of interest rate spells within the individual deposit and loan products. A large share of spells end within one month, but a substantial share last for two years or more.

Third, the average magnitude of an interest rate change is very large (much larger than the average magnitude of price changes for goods and services). This observation underlines the lumpiness of interest rate adjustments, ${ }^{14}$ and the challenges of using partial adjustment models for exploring bank interest rate dynamics.

These findings square well with key findings about price rigidity (see Nakamura and Steinsson, 2008, for example) and point to some important similarities between price and interest rate adjustments that justify our approach of using price dynamic tools to analyze interest rate dynamics.

\footnotetext{
${ }^{13}$ Note that these products are not of merely marginal importance for banks and consumers: with regard to deposits, checking accounts and money market deposit accounts are the major source of retail funding for U.S. banks; with regard to loans, personal loans and credit cards are the ones most closely related to private consumption of non-housing items.

${ }^{14}$ Unfortunately, we cannot compare our findings about interest rate rigidities with similar results from other countries or time periods, since none are available at this time.
} 


\section{The hazard of changing retail interest rates}

Having documented the infrequency and heterogeneity of retail interest rate changes, we turn to an analysis of the hazard rates of changing a retail interest rate, which capture the probability of changing a given retail rate at a certain point in time. The hazard function plots the functional dependence between the time since the last interest rate change and the probability of another change. Formally, the hazard rate is expressed as

$h(t)=P(T=t \mid T \geq t)$

where $P(T=t \mid T \geq t)$ gives the probability that the retail interest rate will change in period $t$ if it has survived until $t-1$. The hazard rate, also known as the conditional failure rate, is computed as:

$h(t)=\frac{f(t)}{1-F(t)}$

where $f(t)$ denotes the probability density function and $F(t)$ denotes the cumulative distribution function.

The hazard rate's property of plotting the functional relation between the conditional probability of a price change and the time since the last one has made it the preferred empirical technique in the recent literature on price dynamics. Alternative theories of the source of price inflexibility generate different predictions for the form of the hazard function. The classical time-dependent model of Calvo 1983 generates a flat form of the hazard function, the Taylor 1980 model of regular price changes generates flat hazard with repeated spikes, while state-dependent price dynamic models result in an upward sloping hazard of changing the price (see Nakamura and Steinsson, 2009 for a discussion). The analysis of the hazard rates can therefore be employed for the empirical discriminations among alternative theoretical models. Unfortunately, the empirical analysis with this regard has so far produced more puzzles than it has resolved since most empirical examinations of the hazard rates have estimated decreasing hazard functions (Alvarez et al 2005; Nakamura and Steinsson 2009) 
inconsistent with both time- and state-dependent pricing theories. Downward sloping hazard functions are typically explained by product heterogeneity: if the hazard for products with very different price durations is estimated jointly, the resulting hazard function has a downward slope since the hazard rate at short durations (when both frequently and seldomly re-priced items are present in the sample) is higher than the hazard rate for longer durations (when all frequently re-priced item have left the sample and we only observe the hazard rates for the less flexible products). The analysis of hazard rates of a finer grid of groups presented by Cavallo (2011) is the only study we are aware of that generates hump-shaped hazards. Surprisingly, however, hazard rates have not yet been applied to interest rate dynamics where, given the relative homogeneity of the products. hazard function estimations are potentially less affected by heterogeneity concerns. ${ }^{15}$

\section{A. Unconditional duration dependence}

We start our examination of the hazard of changing retail interest rates by presenting the nonparametric Kaplan-Meier estimation of the hazard functions for each of the more rigid deposit and loan rates. Chart 5 illustrates the nonparametric hazard rate estimation for the checking account, money market deposit account, personal loan, and fixed credit card rates, respectively. For the sake of parsimony we only present the hazard rates estimated on the samples that do not consider interest changes reversed after one week as ends of the interest rate spells. $^{16}$

Despite the differences in the average duration of the spells across these products, a few similarities are obvious. For all four types of interest rates, we initially observe a statistically significant increase in the hazard rate. After roughly half a year, hazard rates reach a local maximum and slowly decline afterwards. The graphs illustrate a new local maximum after roughly one and one-half years; however, the statistical significance of this second maximum

\footnotetext{
15 Arbatskaya and Baye (2004) is the only paper we know of that presents the hazard function of interest rate spells (in their case, online posted mortgage rates).

${ }_{16}$ Estimates using the full sample of interest rate changes and those excluding sales with a duration of less than four weeks are qualitatively very similar to the hazard rates presented.
} 
is weak. Our estimates of the hump-shaped form of the hazard provide one of the few empirical examples of an increasing hazard function for a price change.

We interpret the estimated hump-shaped form of the hazard function as follows:

During the first six months or so, the hazard of changing the interest rate increases, which implies that rates that have not been changed for longer periods are more likely to be changed. This is consistent with models of price dynamics with fixed menu costs (or, more generally, non-convex adjustment costs), which imply increasing hazard functions (see Nakamura and Steinsson, 2009; and Alvarez et al., 2006, for a review of various hazard functions derived from alternative price-setting models). ${ }^{17}$ After a period of roughly six months, the largest portion of the spells in our sample has ended; we are left with the long spells of the infrequently adjusting banks, and the form of the hazard function is downward sloping.

Note that in these baseline estimations, we control for neither bank heterogeneity (across banks) nor changes in wholesale market interest rates nor any other control variables that could affect either the unobservable optimal retail interest rate or the costs of adjusting the retail interest rate. In the next section, we control for these by fitting a shared frailty model, and we present the resulting impact on estimated hazard rates.

\section{B. Determinants of the hazard of changing retail interest rates}

The availability of firm, market and interest rate data in our empirical framework allows us to extend the analysis to study the determinants of the hazard of changing the retail rates. The exploration of these determinants contains, on the one hand, information on the effect of observed heterogeneity on price dynamics. On the other hand, by incorporating the available information into state-dependency related covariates we can empirically test for the statedependency of the retail rate changes. Classical state-dependent price dynamics models such

\footnotetext{
${ }^{17}$ A menu cost model assumes that an interest rate change is delayed until the deviation of the current retail interest rate offered by the bank from the optimal retail interest rate goes beyond a trigger point, which is related to the menu cost of adjusting the retail interest rate. The probability that a bank will change a given retail interest rate increases in the menu cost model because the current interest rate's deviation from an optimal interest rate is likely to increase with time.
} 
as (Sheshinski and Weiss, 1977, Nakamura and Steinsson 2009) provide the theoretical background for our approach. These assume that a firms' decision to change a price is driven by the trade-off between the costs of deviating from and optimal price (which is a function of the costs and the demand function faced by the firm) and the costs of adjusting the price. Under the assumption of a state-dependent retail interest rate adjustment, a bank will change the retail interest rate if and only if the costs of the deviation of the currently offered retail rate from an unobservable optimal level exceed the costs of adjusting the retail rate. The choice of hazard function covariates that we examine is, therefore, driven by the goal of identifying variables that affect the unobserved optimal retail rate or the adjustment costs. In this context, we have a substantial advantage over the standard price stickiness literature, where finding empirical measures for both the latent optimal price and the adjustment costs is challenging.

We proceed as follows. We assume that the optimal retail interest rate is a function of the general interest rate level. Since banks have some market power in retail loan and deposit markets, the optimal retail rate from a profit-maximizing bank's point of view reflects general interest rate dynamics modified by market power parameters. Although this optimal retail interest rate is not observable, we can empirically approximate the deviation of the actual retail rate from the latent optimum. The approximation is based on the classical statedependency S,s literature's assumption that when a bank changes its retail rates it sets them to the optimal retail rate at the respective point of time. The deviation of the observed retail rate from the optimal retail rate can therefore be approximated by tracking the dynamics of the wholesale rate since the latest retail rate change and controlling for bank and market characteristics. For this purpose we focus on two groups of variables. The first group of variables tracks wholesale interest rate dynamics. The second group includes observed bank and market characteristics as measures of the degree of bank market power which modifies the reaction of the optimal retail rate to changes in the wholesale rate level. 
With regard to the measures of wholesale interest rate dynamics we start by including the cumulative change in the wholesale interest rates between the time of the latest retail rate change and the time of the observation as a covariate. ${ }^{18}$ We use two different rates to represent the wholesale rate. First, we use the rate on three-month Treasury bills (absolute change T-bill rate). Next, we employ the average effective federal funds rate (absolute change fed funds rate) as an alternative wholesale rate. The former is widely employed as a measure of the costs of bank wholesale funding (Berger and Hannan, 1991; Neumark and Sharpe, 1992; and Hutchison and Pennacchi, 1996). The fed funds rate is a proxy for the monetary policy rate and thus the more relevant one from a monetary policy transmission viewpoint.

Obviously, approximating the deviation of the observed retail rate from the latent optimal rate, based solely on the cumulative changes of the wholesale rate, ignores additional features of interest rate dynamics that might affect the optimal rate. To increase the precision of the approximation, we also control for asymmetric reaction to positive and negative wholesale rate changes (as shown by Berger and Hannan, 1991). For this purpose, we generate dummy variables for positive changes in the wholesale rate in the loan rate regression (positive change dummy) and for negative changes in the wholesale rate in the deposit rate regressions (negative change dummy). We include these dummies, together with their cross-products with the absolute cumulative change of the wholesale rate, as covariates in the estimation of the hazard rate. Other possible determinants of the latent optimal rate might be the level of the wholesale rate as well as its volatility and the expectation of the future wholesale rate. We

\footnotetext{
${ }^{18}$ Changes in the wholesale interest rate can also be interpreted as marginal cost changes. Simple theoretical models of banking predict a positive dependence between bank retail deposit and loan rates and wholesale money market rates (see Kiser, 2003). These models assume that loans are the output in a production function that uses retail and wholesale funds as inputs. In other words, the effect of wholesale rate changes on loan rates resembles the effect of changing input prices on the prices of final goods. The effect of wholesale rate changes on deposit rates is motivated by the substitutability of retail deposits and wholesale funds. An alternative view of the production function of the bank assumes that banks issue deposits and sell the accumulated funds in the wholesale market. In that case, the wholesale rate is the price of output, whereas the retail rate is the input price. In both frameworks, an exogenous rise in the wholesale rate is related to an increase in the optimal retail deposit and loan rates offered by the bank. This interpretation, however, ignores a whole range of the bank's non-interest rate costs.
} 
include the following as additional covariates: the T-bill or fed funds rate as a proxy for the wholesale rate; the difference between the 10-year T-bill rate and the 3-month T-bill rate as a proxy for the expected interest rate (a difference that we term the yield curve proxy) and the volatility of the wholesale rate, which is derived from a GARCH $(1,1)$ model run on weekly observations of the wholesale rate. ${ }^{19}$ These other factors related to wholesale rate dynamics have so far been ignored in empirical analyses of retail interest rate dynamics, which have focused on the response to changes in wholesale rates. Their inclusion is also a substantial contribution to the price rigidity literature, where such detailed data on the driving factors of optimal price dynamics is rarely available. ${ }^{20}$

The effect of wholesale rate dynamics on the optimal retail interest rate of individual banks can be modified by the market power the bank exhibits in each local market as well as by the characteristics of the banks. To this end, we expand the set of variables that could affect the duration of retail interest rates by including the second group of variables related to bank and local bank market characteristics as covariates. The inclusion of these variables in the analysis, on the one hand, allows us to track the dynamics of the deviation from an optimal retail rate; on the other hand, it also allows us to address the heterogeneity across banks with regard to their retail rate adjustments. We exploit the substantial variation among these variables in our data to explore their effects on the hazards.

Extant theories underline the effect of monopolistic distortions on price inflexibility. Models of price adjustment (for example, Barro,1972; and Rotemberg and Saloner, 1987) predict a higher frequency of price changes in markets with more competition because the firms in them face more elastic demand. For the banking industry, Berger and Hannan (1991) model the positive relationship between market concentration and interest rate rigidity. Empirically,

\footnotetext{
${ }^{19}$ The GARCH process is estimated for the differences in logarithms of the rates; in each case, all parameters are highly significant and are measured tightly. GARCH-estimated parameters are available from the authors on request.

${ }^{20}$ The retail gasoline market is a good alternative laboratory for examining optimal price dynamics (see Borenstein, Cameron, and Gilbert, 1997).
} 
the positive relationship between market concentration and price rigidity has been shown in the case of markets for goods and services by Carlton (1986), Caucutt, Ghosh, and Kelton (1999), and Bils and Klenow (2004). In the case of bank retail interest rates, Berger and Hannan (1991), Neumark and Sharpe (1992), Mester and Saunder (1995), and de Graeve et al. (2007) present evidence of a positive relationship between market concentration and interest rate rigidity. An explicit analysis of the impact of market structure on the hazard of changing the price has to our knowledge not been presented so far.

The richness of our dataset allows us to distinguish between different proxies for market structure and market power in the estimation, whereas most of the literature uses a single market structure proxy, such as the concentration ratio or the Herfindahl index. In particular, we include the bank's market share in the respective local market, as measured by the share of the bank's retail deposits collected in the local market relative to the total volume of retail deposits issued by all banks in this local market; the objective is to control whether banks with dominant market power adjust their interest rates less frequently. We also include market concentration, as measured by the Herfindahl index, in each of the local markets, since market structure can affect the price setting of all banks operating in a market. ${ }^{21}$

We also control for the number of local markets in which a bank operates. This takes into account the effect of the linked oligopoly hypothesis, which posits that firms operating in numerous markets will adjust prices in each market less frequently, fearing revenge from competitors in all other markets.

We also include as covariates a number of bank characteristics that can affect the speed of interest rate adjustment. In particular, we control for a bank's total size, as measured by the national logarithm of its total assets. The effect of bank size can be ambiguous. On the one hand, if adjustment costs have a lump-sum component at the bank level, larger banks may be

\footnotetext{
${ }^{21}$ As a robustness check, we also control for potential nonlinearities in the hazard rates' reaction to market concentration; we split the sample into interest rates in highly concentrated bank markets and those in lessconcentrated markets. Results are qualitatively the same.
} 
more likely to adjust prices frequently. On the other hand, larger banks bundle different sets of products, and customers' costs of switching away from a larger bank may be higher, so the size of the bank can have an additional pro-rigidity effect apart from its market share. To avoid endogeneity concerns, all bank variable values stem from the Call Report of the preceding quarter, and all market variables from the previous year's Summary of Deposits.

\section{Estimation technique and results}

We estimate the hazard ratios using a semiparametric Cox model with shared frailty at the bank level to control for the possibility of bank-specific random effects in the interest-ratechanging mechanism. ${ }^{22}$ The Cox proportional hazard model is given by

$\mathrm{h}(\mathrm{t} \mid \mathrm{X})=\mathrm{h}_{0}(\mathrm{t}) * \exp (\mathrm{X} \beta)$

where $\mathrm{X}$ is the vector of covariates and $\mathrm{h}_{0}(\mathrm{t})$ denotes the baseline hazard. The Cox proportional model makes no assumption about the form of the baseline hazard. Rather, it explores the proportional innovation to the baseline hazard generated by the covariates value.

The results of these hazard estimations ${ }^{23}$ are illustrated in Table 3 to Table 6 . To facilitate interpretation, the tables report the hazard ratios rather the estimated coefficients $\beta$. The hazard ratio measures the proportional change in the baseline hazard corresponding to the respective covariate. A hazard ratio value higher than unity implies that the hazard of changing the retail rate increases and interest rate durations are shorter, while a hazard ratio value lower than unity corresponds to a lower hazard of changing the retail rate and a longer retail rate duration.

\footnotetext{
${ }^{22}$ Results of the estimations do not significantly change if we do not account for the bank-specific effect and if we include a bank-market random effect rather that a bank random effect.

${ }^{23}$ Here, we present only estimation results based on the samples in which a spell is assumed to continue if it changes in week $t$ but reverses to the same level in week $t+1$. The distribution of the spell durations and the nonparametric hazard estimations for these samples are presented in the middle subpanels of charts 1 to 8 . We have rerun all regressions using the full sample of failures and the sample of failures that are not reversed within four weeks. The results, which are qualitatively the same as those presented in the text, are available from the authors upon request.
} 
For both deposit and loan rates, these results show, consistent with the implications of statedependent pricing theories, that the spells' duration is substantially affected by wholesale rate dynamics. The dynamics' effect, however, differs substantially across products.

In the case of deposit rates (both checking account rates and money market deposit account rates), the cumulated changes in the wholesale rate enter the regression with hazard ratios lower than one, suggesting that large cumulated changes in the wholesale rate reduce the probability of changing the rate. At first glance, this result is striking, but it can be reconciled with a classical state-dependent price when we consider the effect of the sign of the wholesale change and its interaction term with the wholesale rate change magnitude. Both the dummy for a negative wholesale rate change and the interaction term exert a positive effect on the hazard. In sum, the estimated ratios on the wholesale rate change covariates suggest that the probability of changing the deposit rate increases with the absolute value of negative wholesale rate changes. For example, checking account rates are 1.29 times more likely to change if the federal funds rate has changed by -50 basis points than if no federal funds rate change has been cumulated. ${ }^{24}$ The hazard ratios also suggest that when wholesale rates are rising, banks are less likely to change their deposit rates (they postpone the adjustment). The hazard of changing the checking account rate, for example, corresponding to a +50 basis points cumulated federal funds rate change, is only 53 percent of the hazard if there is no federal funds rate change. ${ }^{25}$ These results present very strong evidence of the asymmetric adjustment of deposit rates and confirm the implications of earlier studies based on simple probit and partial-adjustment models (Berger and Hannan, 1991; Neumark and Sharpe, 1992). The fact that the hazard of changing the retail deposit rate reacts negatively to cumulated positive wholesale rate changes is not only a strong indication of asymmetric price dynamics. It also suggests the role of heterogeneity, in the sense that some banks react quickly to small

\footnotetext{
${ }^{24}$ The effect of the relative hazard change is computed as $1.29=\exp (\ln (0.283) * 0.5) * \exp (\ln (5.8382) * 0.5)$.

${ }^{25}$ The effect of the relative hazard change is computed as $0.53=\exp (\ln (0.2823) * 0.5)$.
} 
wholesale rate changes while others do not. The observations with large cumulated wholesale rate changes therefore reflect the behavior only of the banks that re-price less frequently.

When loan rate spells are considered, the absolute value of the wholesale rate change again generates a hazard ratio lower than unity. This effect is modified by the positive effect of a positive wholesale rate change dummy; however, the effect of the cross-product is negative in the case of loan rate durations. The following numerical examples of the hazard of changing the personal loan rate illustrate the effect of wholesale rate changes: A cumulated change of +10 basis points in the federal funds rate will generate a hazard of changing the personal loan rate that is 2.44 times larger than if no federal funds rate change was cumulated; a fed funds rate change of -10 basis points will reduce the hazard of changing the rate by more than 80 percent.

We also find that higher wholesale rate levels increase the duration of deposit rates (that is, they reduce the hazard of changing them), while they decrease loan rate durations. As expected, wholesale rate volatility reduces the duration of both loan and deposit rates. The expectation that wholesale rates will rise, as reflected in a steep yield curve slope, reduces loan rate durations and increases deposit rate durations. The estimated effects of all these features of wholesale rate dynamics are consistent with the notion of an asymmetric reaction to wholesale rate changes. We will review the issue of asymmetry in detail in section 4 .

In estimating the effect of market structure and bank characteristics, we find, in all regression specifications, that bank size is negatively related to the duration of both deposit and loan rate spells. Market share, on the contrary, increases this duration. In sum, these results suggest that banks do change their retail rates less frequently in markets where they have the strongest presence, and this is especially true for small banks (suggesting that regional banks with a strong presence in a few markets have the least flexible policy of setting interest rates). 
The number of markets where a firm operates increases deposit rates' duration. Adding another market "slows" the time to the change in the retail rate by roughly 1.3 percent. On the other hand, the effect of the number of markets on loan rate duration is negative.

Surprisingly, once market share and bank size are taken into account, the market concentration (as measured by the Herfindahl index) has no significant impact on deposit and loan retail rate durations.

Note that the coefficients of the bank and market variables are statistically less significant in the loan rate regressions. We presume that this is the case because our loan rate sample is much smaller than our deposit rate sample. Also, because the sample covers only very large banks in major banking markets, the variation in terms of bank size, market share, number of markets, and market concentration is not enough for tight coefficient estimation. However, it could also be due to an intrinsic difference between loan- and deposit-rate-setting processes. To shed more light on the most likely source of this deviation (significant impact of market structure on deposit rate dynamics, weaker effect of market structure on loan rate dynamics), we re-estimate the hazard rates for checking and money market deposit account rates, but only for the subsample of banks and markets for which we have loan rate observations. In this experiment, all wholesale rate variables turned out to have statistically significant coefficients, similar to those estimated from the full deposit-rate sample. However, none of the bank or local market characteristics entered with a statistically significant coefficient. These variables' lack of significance is, therefore, most likely due to the limited scope of the sample. The comparison of the estimations based on the different samples underscores the importance of using comprehensive samples and casts doubt on the results of studies (such as Hofmann and Mizen, 2004) that are limited to subsamples of the market.

Estimating the Cox proportional model allows us not only to explore the covariates' effect on the hazard rate but also to draw the baseline hazards so as to eliminate the effect of observed heterogeneity. To this end, we conclude the analysis of the hazard of changing the retail rates 
by presenting the baseline hazards for the four products. The baseline hazard rates (illustrated in Chart 6) show substantial differences across products. Once the effects of observables such as wholesale rate dynamics and bank and market characteristics are accounted for, the baseline hazard for loan products is almost zero. This is not surprising, given that we observe loan rates only for a sample of large banks in very large markets. This is not the case for deposit products, where the baseline hazards are substantially higher. In the case of checking account rates-for which we do not observe important product characteristics such as service fees, number of ATMs, and so forth—some unobserved heterogeneity still generates a downward-sloping baseline hazard. The baseline hazard for the MMDA rate changes is upward sloping, which suggests that unobserved heterogeneity is less of an issue for this rather homogenous product.

In sum, our results suggest that wholesale rate dynamics is a key determinant of retail interest rate durations. Adding standard bank and market variables strengthens the model and explains some of the heterogeneity of retail rate adjustments.

\section{Asymmetric interest rate dynamics: A competing risks model investigation}

One of the key observations from the estimated hazard ratios presented in section 3 is that the hazard of changing both loan and deposit rates is asymmetrically affected by positive and negative wholesale rate movements. Asymmetric price adjustment patterns have already been documented for a broad set of products. For example, Petzman (2000) presents evidence, based on a broad range of product categories that prices adjust more quickly to an upward than to a downward cost shock. In the case of retail interest rates the asymmetry in the speed of adjustment to positive and negative wholesale rate changes has been shown by Hannan and Berger (1991) and Hannan (1994).

So far, theory suggests that the observed price adjustment asymmetry results from monopolistic distortion (the optimal rate reacts asymmetrically to marginal cost changes because of the monopoly power of price setting firms). Empirical research, however, fails to 
find that market imperfections have any significant effect on the magnitude of asymmetry (Petzman 2000).

This controversy about the sources of the asymmetry of price dynamics motivates us to revisit the issue. We extend the analysis presented in section 3 and address the asymmetry of price adjustments using a competing risks hazard model that views positive and negative changes as separate events. Although the standard hazard function estimations indicate the existence of asymmetry, pooling positive and negative changes into a single failure event limits their ability to address the sources of the asymmetry. It also limits the ability to examine mutually offsetting effects, such as the effect of factors that increase the probability of a positive change (e.g. positive wholesale rate shocks) combined with the effect of factors that increase the probability of a negative change in the retail rate (e.g. strong market power). The competing risks model improves on this by allowing us to identify the covariates' effect on each of the two "subhazards." It also allows us to identify the variables that reinforce price adjustment asymmetry by comparing the covariates' impact on each of the two subhazards.

Generally, the choice of covariates for the competing risks model follows the strategy presented in chapter 3 . However, we also re-estimate the model for both positive and negative changes of the wholesale rates, separately. The estimation is based on the approach proposed by Fine and Gray (1999), which extends the framework of the classical Cox approach to a semiparametrical estimation of the covariates' effect on baseline subhazards for positive and negative changes respectively. In other words, the Fine and Gray (1999) subhazard estimates present the innovation to the baseline subhazard caused by a unit of the covariate. ${ }^{26}$

The results of the competing risks models for the positive and negative changes in each of the four retail rates are presented in tables 7 to 10 . These results show that a positive (negative)

\footnotetext{
${ }^{26}$ Unfortunately, the classical identification challenges demonstrated by Heckman and Honore (1998) and Honore and Lleras-Muney (2006) challenge the exploration of the other key question that could also have enabled us to relate the asymmetry of interest rate adjustments to heterogeneous adjustment costs, such as analyzing whether banks at high risk of one type of failure (positive) are also at high risk for the other (negative), even after controlling for covariates.
} 
wholesale rate change positively affects the probability of a positive (negative) retail rate change. Also, a negative (positive) wholesale rate change negatively affects the probability of a positive (negative) retail rate change. Thus, the asymmetry emerges from the different magnitudes of the effect of positive and negative wholesale rate changes. In the case of deposit rates, the effect of negative wholesale rate changes is stronger than that of positive rate changes. The opposite is true for loan rates.

So the hazard of positive deposit rate changes is only slightly increased in the case of positive wholesale rate changes. For example, a 0.5 percent cumulative change in the federal funds rate generates the hazard of a positive checking account rate change that is $1.03^{27}$ times larger than the baseline hazard. However, a negative wholesale rate change tremendously increases the probability (all else being equal) of a negative deposit rate change. For example, a -0.5 percent cumulative change in the federal funds rate generates the hazard of a negative checking account rate change that is $2.27^{28}$ times larger than the baseline hazard). The asymmetry is less pronounced in the case of loan rate changes, which, according to the results presented in table 9 and table 10, react with an increased probability of mild positive changes in the cumulated wholesale rate change. For example, a positive federal funds rate change of 0.25 generates the hazard of a positive loan rate change that is 1.08 times higher than the baseline hazard, whereas a fed funds rate change of 0.5 induces a hazard that is 0.79 times the baseline hazard. ${ }^{29}$ Negative interest rate changes substantially decrease the probability of changing the loan rates.

The fact that the hazard function estimates from section 3 showed that positive wholesale rate changes decrease the probability of a deposit rate change, then, reflects the offsetting of the increase in the hazard of positive changes by the decrease in the negative changes hazard, caused by a rise in the wholesale rate level.

\footnotetext{
${ }^{27}$ The effect of the relative subhazard change is computed as $1.03=\exp (\ln (0.935) * 0.5) * \exp (\ln (0.001) * 0.5)$.

${ }^{28}$ The effect of the relative subhazard change is computed as $2.27=$ $\exp (\ln (0.271) * 0.5) * 1.699 * \exp (\ln (6.567) * 0.5)$.

${ }^{29}$ Note that a smaller effect of larger values of the cumulated wholesale rate change could result from heterogeneity, since banks that have not adjusted to smaller changes are less likely to adjust later on.
} 
Among the market-structure and bank-specific control variables, we find that bank size and market concentration do not substantially affect the asymmetry (they reduce the probability of deposit rate increases slightly more than those of deposit rate increase). Market share, on the other hand, has a very important, strong asymmetry-reinforcing effect. These results support the hypothesis of a market-power-driven asymmetry as suggested by the theory. They challenge earlier results, which used industry level measures of market distortions and so failed to identify the role of firm-level market power in reinforcing asymmetric price dynamics. The different signs of the impact of bank size, market share, and market concentration also suggest a complex interaction between bank and market characteristics, which explains the failure of studies based on less detailed data to uncover a relation between monopolistic distortions and asymmetric price dynamics.

\section{Conclusion}

In this paper, we examine a novel dataset on retail interest rates and use it as an example of retail prices to explore several aspects of price-setting behavior. We study the functional form of the hazard of changing a price, the reaction of this hazard to firm and market characteristics, and the sources of price dynamics' asymmetry. The major advantage of using retail deposit rates as price examples is the extraordinary richness of available data, which allows us to explore the effect of product-, firm- and market-level characteristics on the duration of price spells in a uniform analytical framework.

We find that retail interest rates, such as checking account rates, money market deposit account rates, personal loan rates, and fixed credit card rates, have a mean duration in the range of three to four months. The estimated hazard function of changing the retail rates increases for roughly the first six months and decreases after that. The hazard is significantly affected by bank and market structure characteristics. And last but not least, the effect of money market interest rate dynamics on retail interest rates is strongly asymmetrical, and the magnitude of the asymmetry is related to monopolistic distortions. 
These results contribute substantially to the price rigidity literature which has, so far, used less detailed data that do not allow identification either of the relation between firm and market characteristics and the hazard of price changes or of the sources of price adjustment asymmetries. Besides contributing to the price rigidity literature, our analysis contributes to the literature on interest rate dynamics by overcoming the econometric pitfalls associated with the use of smooth adjustment techniques such as cointegration in analyzing interest rate dynamics, which is obviously characterized by lumpy adjustments.

Two policy implications emerge from our results. First, the documented state-dependency of retail rate dynamics suggests important implications for aggregate interest rate dynamics by proposing that those banks with the largest deviation from the optimum are most likely to adjust their retail rates. Policies targeting a change in the retail rate should, therefore, account for the distribution of the deviations from the optimum rate for the population of banks as well as for the possibility that a substantial share of banks may not react at all to a monetary policy rate change if such a change does not shift their optimal retail rate substantially. Second, by illustrating the role of market structure in the retail rate adjustment process, we show the importance of bank market structure dynamics for monetary policy transmission. Our analysis in this paper could be characterized as "reduced form," in the sense that the estimates have few structural interpretations. However, the hazard functions that we estimate provide a point of departure to a variety of structural extensions, such as exploration of the effect of lumpy, bank-level interest rate adjustments on aggregate interest rate dynamics and the empirical estimation of the magnitude of the adjustment costs. Further, because our results suggest the importance of unobserved heterogeneity in determining price changes, our estimating approach can easily be expanded to include unobserved heterogeneity of a known parametric form.

All of this suggests that duration analysis, along with our high-frequency data, can be an important first step towards developing a structural model of interest-rate determination. 
Constructing such a model is a scheduled extension of this research project. Potentially, these results point to important similarities between the microeconometric properties of price and interest-rate dynamics, which can be employed in modeling the mechanism of monetary policy transmission. 


\section{Literature}

Álvarez, L., E. Dhyne, M. Hoeberichts, C. Kwapil, H. Le Bihan, P. Lünnemann, F. Martins, R. Sabbatini, H. Stahl, P. Vermeulen, and J. Vilmunen (2005). Sticky prices in the Euro Area: A Summary of New Micro Evidence, Journal of the European Economic Association, vol. 4: 575-584

Alvarez, L.J., P. Burriel, and I. Hernando (2005). Do Decreasing Hazard Functions for Price Changes Make Sense? Banco de Espana Working Paper 0508

Alvarez, F., Lippi, F. and L. Paciello (2010): Optimal Price Setting with Observation and Menu Costs, NBER Working Paper 15852

Arbatskaya, M. and M. Baye (2004). Are Prices "Sticky" Online? Market Structure Effects and Asymmetric Responses to Cost Shocks in Online Mortgage Markets, International Journal of Industrial Organization, vol. 22 (10): 1443-1462

Berger, A., and T. Hannan (1991). The Rigidity of Prices: Evidence from the Banking Industry, American Economic Review, vol. 81(4): 938-945

Bils, M. and P. J. Klenow (2004) “Some Evidence on the Importance of Sticky Prices," Journal of Political Economy, 112: 947-985

Calem, P., Gordy, M. and L. Mester (2006): Switching Costs and Advarce Selection in the Market for Credit Cards: New Evidence, Journal of Banking and Finance, 30 (6): 1653-1685

Calvo, G. A. (1983) “Staggered Prices in a Utility-Maximizing Framework,”Journal of Monetary Economics, 12, 383-398

Caplin, A. and D. Spulber (1987) "Menu Costs and the Neutrality of Money," Quarterly Journal of Economics, 102, 703-725.

Cavallo, A. (2011) : Scraped Data and Sticky Prices, mimeo

De Graeve, F., O. De Jonghe, and R.V. Vennet (2007). Competition, Transmission, and Bank Pricing Policies: Evidence from Belgian Loan and Deposit Markets, Journal of Banking and Finance, vol. 31(1): 259-278

Fine, J. P., and R. J. Gray (1999). A Proportional Hazards Model for the Subdistribution of a Competing Risk, Journal of the American Statistical Association, vol. 94: 496-509

Golosov, M., and R. E. Lucas Jr. (2007). Menu Costs and Phillips Curves, Journal of Political Economy, vol. 115 (171-199)

Heckman, J., and B. Honore (1998). The Identifiability of the Competing Risks Model, Biometrica, vol. 76: 325-330 
Hofmann, B., and P. Mizen (2004). Interest Rate Pass Through in the Monetary Transmission Mechanism: UK Banks' and Building Societies' Retail Rates, Economica, vol. 71, 99-125

Honore, B. and A. Lleras-Muney (2006). Bounds in Competing Risks Models and the War on Cancer”, Econometrica, vol 74 (6), 1675-1698

Mankiw, N. G. and R. Reis (2002) "Sticky Information Versus Sticky Prices: A Proposal to Replace the New Keynesian Phillips Curve," Quarterly Journal of Economics, 117, 1295-1328

Mester, L. (1994): Why are Credit Card Rates Sticky? Economic Theory, vol. 4: 505-530

Mester, L., and A. Saunders (1995). When Does the Prime Rate Change? Journal of Banking and Finance, vol. 19: 743-764

Mojon, B. (2000). Financial Structure and the Interest Rate Channel of the ECB Monetary Policy, ECB Working Paper 40/2000

Nakamura, E.. and J. Steinsson (2009). Five Facts about Prices: A Reevaluation of Menu Costs Models, forthcoming, Quarterly Journal of Economics

Nakamura, E., and D. Zerom (2010). “Accounting for Incomplete Pass-Through,” Review of Economic Studies, vol. 77(3): 1192-1230

Neumark, D., and S. Sharpe (1992). Market Structure and the Nature of Price Rigidity: Evidence from the Market for Consumer Deposits, Quarterly Journal of Economics, vol. 107(2): 657-680

Sheshinski, E., and Y. Weiss (1977). "Inflation and Costs of Price Adjustment," Review of Economic Studies, vol. 44(2): 287-303

Slade, M. (1998). "Optimal Pricing with Costly Adjustment and Persistent Effects: Empirical Evidence from Retail-Grocery Prices," Review of Economic Studies, vol. 65(1): 87-107

Taylor, J. B. (1980): “Aggregate Dynamics and Staggered Contracts,” Journal of Political Economy, 88: $1-23$ 
Table 1: Average duration of interest rate spells and average rate change

\begin{tabular}{|c|c|c|c|c|}
\hline Product & $\begin{array}{r}\text { average } \\
\text { duration (in } \\
\text { weeks) }\end{array}$ & $\begin{array}{r}\text { average } \\
\text { change (in \%) }\end{array}$ & $\begin{array}{r}\text { average } \\
\text { rate }\end{array}$ & $\begin{array}{r}\text { average } \\
\text { change } \\
\text { relative to } \\
\text { average } \\
\text { rate }\end{array}$ \\
\hline \multicolumn{5}{|l|}{ deposits } \\
\hline checking accounts & 17.71 & 0.16 & 0.53 & 0.30 \\
\hline MMDA & 12.76 & 0.26 & 1.07 & 0.24 \\
\hline CD 3 months & 7.87 & 0.33 & 2.33 & 0.14 \\
\hline CD 12 months & 6.08 & 0.35 & 2.96 & 0.12 \\
\hline \multicolumn{5}{|l|}{ loans } \\
\hline auto loan & 9.87 & 0.87 & 7.67 & 0.11 \\
\hline arm 1 year & 4.88 & 0.52 & 3.82 & 0.14 \\
\hline heloc & 8.15 & 0.60 & 12.32 & 0.05 \\
\hline mortgage 15 years & 3.34 & 0.25 & 5.83 & 0.04 \\
\hline personal & 11.13 & 1.47 & 12.32 & 0.12 \\
\hline fixed credit card & 10.08 & 0.87 & 7.56 & 0.12 \\
\hline
\end{tabular}

Source: Authors' computations based on BankRate Monitor data. 
Table 2: Number of spells and number of time changes reversed within four weeks

\begin{tabular}{|c|c|c|c|c|c|c|}
\hline Product & $\begin{array}{l}\text { total number } \\
\text { of spells }\end{array}$ & $\begin{array}{l}\text { total number } \\
\text { of } \\
\text { uncensored } \\
\text { spells }\end{array}$ & $\begin{array}{l}\text { number of } \\
\text { "sales" with } \\
\text { one week } \\
\text { duration }\end{array}$ & $\begin{array}{l}\text { number of } \\
\text { "sales" with } 2 \\
\text { weeks } \\
\text { duration }\end{array}$ & $\begin{array}{l}\text { number of } \\
\text { "sales" with } 3 \\
\text { weeks } \\
\text { duration }\end{array}$ & $\begin{array}{l}\text { number of } \\
\text { "sales" with } 4 \\
\text { weeks } \\
\text { duration }\end{array}$ \\
\hline \multicolumn{7}{|l|}{ deposits } \\
\hline cheching account & 8084 & 5714 & 628 & 149 & 107 & 70 \\
\hline MMDA & 14433 & 11814 & 1600 & 240 & 257 & 103 \\
\hline \multicolumn{7}{|l|}{ loans } \\
\hline personal & 797 & 642 & 134 & 48 & 20 & 12 \\
\hline fixed credit card & 709 & 565 & 79 & 21 & 12 & 15 \\
\hline
\end{tabular}

Source: Authors' calculations based on BankRate Monitor data. 
Table 3: Wholesale rate changes and the hazard of changing the checking account rate: COX proportional hazard ratios

\begin{tabular}{lcrrr}
\hline & wholesale rate=T-Bill 3 & \multicolumn{2}{c}{ wholesale rate=Fed } \\
\hline & $\begin{array}{c}\text { Hazard } \\
\text { ratio }\end{array}$ & $\begin{array}{r}\text { standard } \\
\text { error }\end{array}$ & $\begin{array}{r}\text { Hazard } \\
\text { ratio }\end{array}$ & $\begin{array}{r}\text { standard } \\
\text { error }\end{array}$ \\
\hline absolute change wholesale rate & $0.1100^{* * *}$ & 0.0070 & $0.2823^{* * *}$ & 0.0109 \\
dummy for negative change & 1.0301 & 0.0438 & $1.3760^{* *}$ & 0.0506 \\
negative change*absolute change & $5.8382^{* * *}$ & 0.4216 & $5.2885^{* * *}$ & 0.3757 \\
wholesale rate & $0.8664^{* * *}$ & 0.0225 & $0.9182^{* * *}$ & 0.0226 \\
yield curve & $0.6445^{* * *}$ & 0.0253 & $0.6879^{* * *}$ & 0.0262 \\
wholesale rate volatility & $6.0930^{* * *}$ & 1.0410 & $1.0006^{* * *}$ & 0.0000 \\
bank size & $1.0684^{* *}$ & 0.0139 & $1.0978^{* * *}$ & 0.0141 \\
herfindahl & 1.3528 & 0.2922 & 1.4203 & 0.3130 \\
market share & $0.6672 * * *$ & 0.1074 & $0.6562 * *$ & 0.1050 \\
number of markets & $0.9888^{* * *}$ & 0.0012 & $0.9855^{* * *}$ & 0.0011 \\
\hline \# Observations & $\mathbf{1 3 8 4 1 7}$ & & $\mathbf{1 3 8 6 5 2}$ & \\
\# spells & $\mathbf{6 4 8 3}$ & & 6483 & \\
LR Chi(2) & $\mathbf{7 3 6 . 3 7}$ & & $\mathbf{6 3 8 . 7 1}$ & \\
\hline \hline
\end{tabular}

Note: COX proportional semi-parametric estimation of the hazard of changing the retail rate based on a sample of spells considering only changes which are not reversed within one week as spell "ends". Hazard ratios higher than unity imply an increased hazard of changing the retail rate. Hazard ratios lower than unity imply a lower probability of changing the retail rate and thus more rigid retail rates. 
Table 4: Wholesale rate changes and the hazard of changing the money market deposit account rate: COX proportional hazard ratios

\begin{tabular}{lcrrr}
\hline & \multicolumn{2}{c}{ wholesale rate=T-Bill 3 } & \multicolumn{2}{c}{ wholesale rate=Fed } \\
\hline & $\begin{array}{c}\text { Hazard } \\
\text { ratio }\end{array}$ & $\begin{array}{r}\text { standard } \\
\text { error }\end{array}$ & $\begin{array}{r}\text { Hazard } \\
\text { ratio }\end{array}$ & $\begin{array}{r}\text { standard } \\
\text { error }\end{array}$ \\
\hline absolute change wholesale rate & $0.524^{* * *}$ & 0.018 & $0.184^{* * *}$ & 0.006 \\
dummy for negative change & $1.669^{* * *}$ & 0.046 & $0.914^{* *}$ & 0.023 \\
negative change*absolute change & $0.089^{* * *}$ & 0.006 & $9.301^{* * *}$ & 0.581 \\
wholesale rate & $0.853^{* * *}$ & 0.016 & $0.889^{* * *}$ & 0.015 \\
yield curve & $0.632^{* * *}$ & 0.016 & $0.657^{* * *}$ & 0.017 \\
wholesale rate volatility & $2.491^{* * *}$ & 1.021 & $4.822^{* * *}$ & 1.137 \\
bank size & $1.080^{* * *}$ & 0.010 & $1.079 * * *$ & 0.010 \\
herfindahl & 0.832 & 0.132 & 0.836 & 0.132 \\
market share & 0.924 & 0.103 & 0.952 & 0.105 \\
number of markets & $0.989 * * *$ & 0.001 & $0.988 * * *$ & 0.001 \\
\hline \# Observations & $\mathbf{1 6 0 1 8 8}$ & & $\mathbf{1 6 0 1 8 8}$ & \\
\# spells & $\mathbf{9 1 0 5}$ & & $\mathbf{9 1 0 5}$ & \\
LR Chi(2) & $\mathbf{7 3 6 1 . 0 5}$ & & $\mathbf{4 7 4 5 . 0 7}$ & \\
\hline \hline
\end{tabular}

Note: COX proportional semi-parametric estimation of the hazard of changing the retail rate based on a sample of spells considering only changes which are not reversed within one week as spell "ends". Hazard ratios higher than unity imply an increased hazard of changing the retail rate. Hazard ratios lower than unity imply a lower probability of changing the retail rate and thus more rigid retail rates. 
Table 5: Wholesale rate changes and the hazard of changing the personal loan rate: COX proportional hazard ratios

wholesale rate=T-Bill 3 wholesale rate=Fed funds

\begin{tabular}{lcrrr}
\hline & $\begin{array}{c}\text { Hazard } \\
\text { ratio }\end{array}$ & $\begin{array}{r}\text { standard } \\
\text { error }\end{array}$ & $\begin{array}{r}\text { Hazard } \\
\text { ratio }\end{array}$ & $\begin{array}{r}\text { standard } \\
\text { error }\end{array}$ \\
\hline absolute change wholesale rate & $0.412^{* * *}$ & 0.063 & $0.714^{* * *}$ & 0.070 \\
dummy for positive change & $3.992 * * *$ & 0.499 & $4.221^{* * *}$ & 0.512 \\
positive change*absolute change & $0.019 * * *$ & 0.012 & $0.010 * * *$ & 0.006 \\
wholesale rate & $1.290 * * *$ & 0.111 & $1.576 * * *$ & 0.124 \\
yield curve & $1.568 * * *$ & 0.186 & $2.077 * * *$ & 0.251 \\
wholesale rate volatility & 7.050 & 12.400 & $7.316 * * *$ & 10.544 \\
bank size & $1.076 *$ & 0.051 & $1.079 *$ & 0.049 \\
herfindahl & 0.614 & 0.609 & 0.579 & 0.579 \\
market share & $0.076 * * *$ & 0.043 & 0.065 & 0.037 \\
number of markets & $1.020 * * *$ & 0.003 & $1.022 * *$ & 0.003 \\
\hline \# Observations & 4862 & & 5582 & 625 \\
\# spells & 527 & & 367.98 & \\
LR Chi(2) & 498.03 & & & \\
\hline \hline
\end{tabular}

Note: COX proportional semi-parametric estimation of the hazard of changing the retail rate based on a sample of spells considering only changes which are not reversed within one week as spell "ends". Hazard ratios higher than unity imply an increased hazard of changing the retail rate. Hazard ratios lower than unity imply a lower probability of changing the retail rate and thus more rigid retail rates. 
Table 6: Wholesale rate changes and the hazard of changing the fixed credit card rate: COX proportional hazard ratios

wholesale rate $=$ T-Bill 3 month wholesale rate $=$ Fed funds

\begin{tabular}{lcccr}
\hline & Hazard ratio & $\begin{array}{r}\text { standard } \\
\text { error }\end{array}$ & $\begin{array}{c}\text { Hazard } \\
\text { ratio }\end{array}$ & $\begin{array}{r}\text { standard } \\
\text { error }\end{array}$ \\
\hline absolute change wholesale rate & $0.159^{* * *}$ & 0.036 & $0.568^{* * *}$ & 0.068 \\
dummy for positive change & $2.503^{* * *}$ & 0.327 & $1.890^{* * *}$ & 0.225 \\
positive change*absolute change & $0.003^{* * *}$ & 0.002 & $0.000^{* * *}$ & 0.000 \\
wholesale rate & $2.375^{* * *}$ & 0.224 & $1.872 * * *$ & 0.154 \\
yield curve & $2.272^{* * *}$ & 0.298 & $1.787^{* * *}$ & 0.229 \\
wholesale rate volatility & $1.694^{* * *}$ & 1.024 & $1.000^{* * *}$ & 0.000 \\
bank size & $1.122^{* *}$ & 0.051 & $1.091^{*}$ & 0.049 \\
herfindahl & 0.917 & 0.814 & 0.555 & 0.479 \\
market share & 0.724 & 0.390 & 1.013 & 0.549 \\
number of markets & $1.005 * *$ & 0.003 & $1.006 * *$ & 0.003 \\
\hline \# Observations & $\mathbf{4 9 8 2}$ & & $\mathbf{4 9 8 2}$ & \\
\# spells & $\mathbf{5 4 3}$ & & $\mathbf{5 4 3}$ & $\mathbf{2 7 7 . 9 5}$ \\
LR Chi(2) & $\mathbf{5 2 9 . 7 2}$ & & & \\
\hline \hline
\end{tabular}

Note: COX proportional semi-parametric estimation of the hazard of changing the retail rate based on a sample of spells considering only changes which are not reversed within one week as spell "ends". Hazard ratios higher than unity imply an increased hazard of changing the retail rate. Hazard ratios lower than unity imply a lower probability of changing the retail rate and thus more rigid retail rates. 
Table 7: Competing risks model estimation of the subhazard ratios for positive and negative changes of the checking account rate

\begin{tabular}{|c|c|c|c|c|c|c|c|c|}
\hline & \multicolumn{8}{|c|}{ Positive change hazard } \\
\hline & \multicolumn{4}{|c|}{ wholesale rate $=T$-Bill 3 month rate } & \multicolumn{4}{|c|}{ wholesale rate=Fed funds rate } \\
\hline & $\begin{array}{r}\text { Hazard } \\
\text { ratio }\end{array}$ & $\begin{array}{r}\text { standard } \\
\text { error }\end{array}$ & $\begin{array}{l}\text { Hazard } \\
\text { ratio }\end{array}$ & $\begin{array}{r}\text { standard } \\
\text { error }\end{array}$ & $\begin{array}{r}\text { Hazard } \\
\text { ratio }\end{array}$ & $\begin{array}{r}\text { standard } \\
\text { error }\end{array}$ & $\begin{array}{r}\text { Hazard } \\
\text { ratio }\end{array}$ & $\begin{array}{r}\text { standard } \\
\text { error }\end{array}$ \\
\hline absolute change wholesale rate & $0.289 * * *$ & 0.021 & $0.244^{* * *}$ & 0.059 & $0.382 * * *$ & 0.025 & $0.276 * * *$ & 0.037 \\
\hline dummy for negative change & $0.836 *$ & 0.085 & & & 0.990 & 0.130 & & \\
\hline negative change ${ }^{*}$ absolute change & 0.844 & 0.214 & & & $0.339 *$ & 0.214 & & \\
\hline dummy for positive change & & & $1.197 *$ & 0.122 & & & 1.079 & 0.101 \\
\hline positive change*absolute change & & & 1.185 & 0.301 & & & $2.783 * *$ & 1.239 \\
\hline wholesale rate & $0.725 * * *$ & 0.042 & 0.725 *** & 0.042 & $0.796 * * *$ & 0.045 & $0.841 * * *$ & 0.052 \\
\hline yield curve & $0.574 * * *$ & 0.051 & $0.574^{* * *}$ & 0.051 & $0.684 * * *$ & 0.061 & $0.701 * * *$ & 0.066 \\
\hline wholesale rate volatility & $0.000 * * *$ & 0.000 & $7.090 * * *$ & 2.050 & $1.000 * * *$ & 0.000 & $1.000 * * *$ & 0.000 \\
\hline bank size & $1.125 * * *$ & 0.029 & $1.125 * * *$ & 0.029 & $1.136 * * *$ & 0.030 & $1.138 * * *$ & 0.030 \\
\hline herfindahl & $2.493 * *$ & 0.980 & $2.493 * *$ & 0.980 & $2.346 * *$ & 0.918 & $2.411 * *$ & 0.940 \\
\hline market share & $0.530 *$ & 0.193 & $0.530 *$ & 0.193 & $0.524 *$ & 0.189 & $0.522 *$ & 0.188 \\
\hline number of markets & $0.981 * * *$ & 0.002 & $0.981 * * *$ & 0.002 & $0.979 * * *$ & 0.002 & $0.979 * * *$ & 0.002 \\
\hline \# Observations & 138417 & & 138417 & & 138417 & & 138417 & \\
\hline \# failures & 979 & & 979 & & 979 & & 979 & \\
\hline \multirow[t]{4}{*}{ LR Chi(2) } & 560.5 & & 560.61 & & 529.71 & & 489.7 & \\
\hline & \multicolumn{8}{|c|}{ Negative change hazard } \\
\hline & \multicolumn{4}{|c|}{ wholesale rate $=\mathrm{T}$-Bill 3 month rate } & \multicolumn{4}{|c|}{ wholesale rate=Fed funds rate } \\
\hline & $\begin{array}{r}\text { Hazard } \\
\text { ratio } \\
\end{array}$ & $\begin{array}{r}\text { standard } \\
\text { error } \\
\end{array}$ & $\begin{array}{r}\text { Hazard } \\
\text { ratio } \\
\end{array}$ & $\begin{array}{r}\text { standard } \\
\text { error } \\
\end{array}$ & $\begin{array}{r}\text { Hazard } \\
\text { ratio } \\
\end{array}$ & $\begin{array}{r}\text { standard } \\
\text { error } \\
\end{array}$ & $\begin{array}{r}\text { Hazard } \\
\text { ratio } \\
\end{array}$ & $\begin{array}{r}\text { standard } \\
\text { error } \\
\end{array}$ \\
\hline absolute change wholesale rate & 0.044 & 0.006 & $0.702 * * *$ & 0.028 & $0.271 * * *$ & 0.012 & $0.935 * * *$ & 0.025 \\
\hline dummy for negative change & 1.060 & 0.059 & & & $1.699 * * *$ & 0.080 & & \\
\hline negative change ${ }^{\star}$ absolute change & 15.810 & 2.278 & & & $6.567^{* * *}$ & 0.488 & & \\
\hline dummy for positive change & & & 0.944 & 0.053 & & & 1.071 & 0.049 \\
\hline positive change*absolute change & & & $0.063 * * *$ & 0.009 & & & $0.000 * * *$ & 0.000 \\
\hline wholesale rate & 0.936 & 0.033 & $0.936 * *$ & 0.033 & $0.977 * * *$ & 0.030 & $0.735 * * *$ & 0.024 \\
\hline yield curve & 0.697 & 0.036 & $0.697 * * *$ & 0.036 & $0.727 * * *$ & 0.035 & $0.541 * * *$ & 0.026 \\
\hline wholesale rate volatility & 2.600 & 1.110 & $2.600 * * *$ & 1.100 & $1.001 * * *$ & 0.000 & $1.001 * * *$ & 0.000 \\
\hline bank size & 1.061 & 0.015 & $1.061 * * *$ & 0.015 & $1.094 * * *$ & 0.015 & $1.080 * * *$ & 0.015 \\
\hline herfindahl & 1.130 & 0.287 & 1.130 & 0.287 & 1.175 & 0.312 & 1.064 & 0.278 \\
\hline market share & 0.682 & 0.131 & $0.682 * *$ & 0.131 & $0.682 * * *$ & 0.129 & $0.712 *$ & 0.136 \\
\hline number of markets & 0.990 & 0.001 & $0.990 * * *$ & 0.001 & $0.987 * * *$ & 0.001 & $0.989 * * *$ & 0.001 \\
\hline \# Observations & 138417 & & 138417 & & 138417 & & 138417 & \\
\hline \# failures & 3162 & & 3162 & & 3162 & & 3162 & \\
\hline LR Chi(2) & 2327.08 & & 2327.09 & & 3435.66 & & 1557.88 & \\
\hline
\end{tabular}

Note: Semi-parametric estimation of the subhazards of positive and negative retail rate changes based on a sample of spells considering only changes which are not reversed within one week as spell "ends". Hazard ratios higher than unity imply an increased hazard of changing the retail rate. Hazard ratios lower than unity imply a lower probability of changing the retail rate and thus more rigid retail rates. 
Table 8: Competing risks model estimation of the subhazard ratios for positive and negative changes of the MMDA rate

\begin{tabular}{|c|c|c|c|c|c|c|c|c|}
\hline & \multicolumn{8}{|c|}{ Positive change hazard } \\
\hline & \multicolumn{4}{|c|}{ wholesale rate $=T$-Bill 3 month rate } & \multicolumn{4}{|c|}{ wholesale rate=Fed funds rate } \\
\hline & $\begin{array}{r}\text { Hazard } \\
\text { ratio }\end{array}$ & $\begin{array}{r}\text { standard } \\
\text { error }\end{array}$ & $\begin{array}{r}\text { Hazard } \\
\text { ratio }\end{array}$ & $\begin{array}{r}\text { standard } \\
\text { error }\end{array}$ & $\begin{array}{r}\text { Hazard } \\
\text { ratio }\end{array}$ & $\begin{array}{r}\text { standard } \\
\text { error }\end{array}$ & $\begin{array}{r}\text { Hazard } \\
\text { ratio }\end{array}$ & $\begin{array}{r}\begin{array}{r}\text { standard } \\
\text { error }\end{array} \\
\end{array}$ \\
\hline absolute change wholesale rate & $0.120^{* * *}$ & 0.008 & $0.489 * * *$ & 0.074 & $0.203 * * *$ & 0.011 & $0.749 * * *$ & 0.065 \\
\hline dummy for negative change & $0.217^{* * *}$ & 0.016 & & & $0.339 * * *$ & 0.026 & & \\
\hline negative change*absolute change & $4.094 * * *$ & 0.689 & & & $3.919 * * *$ & 1.271 & & \\
\hline dummy for positive change & & & $4.609 * * *$ & 0.330 & & & $3.987 * * *$ & 0.271 \\
\hline positive change ${ }^{*}$ absolute change & & & $0.244 * * *$ & 0.041 & & & $0.227^{* * *}$ & 0.024 \\
\hline wholesale rate & $0.719 * * *$ & 0.025 & $0.719 * * *$ & 0.025 & $0.751 * * *$ & 0.024 & $0.739 * * *$ & 0.024 \\
\hline yield curve & $0.507 * * *$ & 0.024 & $0.507 * * *$ & 0.024 & $0.513 * * *$ & 0.025 & $0.500 * * *$ & 0.025 \\
\hline wholesale rate volatility & 0.000 & 0.000 & 0.000 & 0.000 & 1.192 & 1.285 & 0.720 & 0.764 \\
\hline bank size & $1.053 * * *$ & 0.017 & $1.053 * * *$ & 0.017 & $1.035 * *$ & 0.017 & $1.033 * *$ & 0.017 \\
\hline herfindahl & 0.995 & 0.279 & 0.995 & 0.279 & 1.043 & 0.284 & 1.030 & 0.281 \\
\hline market share & 0.876 & 0.177 & 0.876 & 0.177 & 0.798 & 0.160 & 0.776 & 0.156 \\
\hline number of markets & $0.991 * * *$ & 0.001 & $0.991 * * *$ & 0.001 & $0.991 * * *$ & 0.001 & $0.992 * * *$ & 0.001 \\
\hline \# Observations & 160188 & & 160188 & & 160188 & & 160188 & \\
\hline \# failures & 3362 & & 3362 & & 3362 & & 3362 & \\
\hline \multirow[t]{4}{*}{ LR Chi(2) } & 1552.73 & & 1552.73 & & 1264.12 & & 1522.87 & \\
\hline & \multicolumn{8}{|c|}{ Negative change hazard } \\
\hline & \multicolumn{4}{|c|}{ wholesale rate $=\mathrm{T}$-Bill 3 month rate } & \multicolumn{4}{|c|}{ wholesale rate=Fed funds rate } \\
\hline & $\begin{array}{r}\text { Hazard } \\
\text { ratio }\end{array}$ & $\begin{array}{r}\text { standard } \\
\text { error }\end{array}$ & $\begin{array}{r}\text { Hazard } \\
\text { ratio }\end{array}$ & $\begin{array}{r}\text { standard } \\
\text { error }\end{array}$ & $\begin{array}{r}\text { Hazard } \\
\text { ratio }\end{array}$ & $\begin{array}{r}\text { standard } \\
\text { error }\end{array}$ & $\begin{array}{r}\text { Hazard } \\
\text { ratio }\end{array}$ & $\begin{array}{r}\text { standard } \\
\text { error }\end{array}$ \\
\hline absolute change wholesale rate & $0.011 * * *$ & 0.002 & $0.559 * * *$ & 0.022 & $0.191 * * *$ & 0.009 & $0.877 * * *$ & 0.020 \\
\hline dummy for negative change & $0.848 * * *$ & 0.032 & $* * *$ & & $1.427 * * *$ & 0.049 & & \\
\hline negative change ${ }^{*}$ absolute change & $51.526 * * *$ & 9.208 & $* * *$ & & $10.365 * * *$ & 1.021 & & \\
\hline dummy for positive change & & & 1.179 & 0.044 & & & $1.153 * * *$ & 0.038 \\
\hline positive change ${ }^{*}$ absolute change & & & 0.019 & 0.003 & & & $0.034 * * *$ & 0.004 \\
\hline wholesale rate & 0.971 & 0.024 & 0.971 & 0.024 & 0.995 & 0.021 & $0.938 * * *$ & 0.022 \\
\hline yield curve & $0.762 * * *$ & 0.026 & $0.762 * * *$ & 0.026 & $0.784 * * *$ & 0.026 & $0.735 * * *$ & 0.025 \\
\hline wholesale rate volatility & $6.200 * * *$ & 1.760 & $6.200 * * *$ & 1.760 & $6.980 * * *$ & 1.737 & $3.153 * * *$ & 7.451 \\
\hline bank size & $1.098 * * *$ & 0.013 & $1.098 * * *$ & 0.013 & $1.105 * * *$ & 0.013 & $1.098 * * *$ & 0.012 \\
\hline herfindahl & 0.793 & 0.166 & 0.793 & 0.166 & 0.741 & 0.156 & 0.787 & 0.163 \\
\hline market share & 0.862 & 0.123 & 0.862 & 0.123 & 0.958 & 0.137 & $0.793 *$ & 0.114 \\
\hline number of markets & $0.987 * * *$ & 0.001 & $0.987 * * *$ & 0.001 & $0.987 * * *$ & 0.001 & $0.988 * * *$ & 0.001 \\
\hline \# Observations & 160188 & & 160188 & & 160188 & & 160188 & \\
\hline \# failures & 5690 & & 5690 & & 5690 & & 5690 & \\
\hline LR Chi(2) & 4295.08 & & 4295.9 & & 4110.18 & & 2233.13 & \\
\hline
\end{tabular}

Note: Semi-parametric estimation of the subhazards of positive and negative retail rate changes based on a sample of spells considering only changes which are not reversed within one week as spell "ends". Hazard ratios higher than unity imply an increased hazard of changing the retail rate. Hazard ratios lower than unity imply a lower probability of changing the retail rate and thus more rigid retail rates. 
Table 9: Competing risks model estimation of the subhazard ratios for positive and negative changes of the personal loan rate

\begin{tabular}{|c|c|c|c|c|c|c|c|c|}
\hline & \multicolumn{8}{|c|}{ Positive change hazard } \\
\hline & \multicolumn{4}{|c|}{ wholesale rate=T-Bill 3 month rate } & \multicolumn{4}{|c|}{ wholesale rate=Fed funds rate } \\
\hline & $\begin{array}{r}\text { Hazard } \\
\text { ratio }\end{array}$ & $\begin{array}{r}\text { standard } \\
\text { error }\end{array}$ & $\begin{array}{r}\text { Hazard } \\
\text { ratio }\end{array}$ & $\begin{array}{r}\text { standard } \\
\text { error }\end{array}$ & $\begin{array}{r}\text { Hazard } \\
\text { ratio }\end{array}$ & $\begin{array}{r}\text { standard } \\
\text { error }\end{array}$ & $\begin{array}{r}\text { Hazard } \\
\text { ratio }\end{array}$ & $\begin{array}{r}\text { standard } \\
\text { error }\end{array}$ \\
\hline absolute change wholesale rate & $0.129 *$ & 0.145 & $0.124^{* * *}$ & 0.089 & $0.158^{* * *}$ & 0.106 & $0.184^{* * *}$ & 0.091 \\
\hline dummy for negative change & $0.338 * * *$ & 0.104 & & & $0.606 *$ & 0.161 & & \\
\hline negative change ${ }^{\star}$ absolute change & 0.961 & 1.326 & & & 1.161 & 0.991 & & \\
\hline dummy for positive change & & & $2.957^{* * *}$ & 0.912 & & & $1.650 * *$ & 0.439 \\
\hline positive change ${ }^{\star}$ absolute change & & & 1.041 & 1.437 & & & 0.861 & 0.735 \\
\hline wholesale rate & 0.839 & 0.174 & 0.839 & 0.174 & $1.496 * * *$ & 0.237 & $1.496 * *$ & 0.237 \\
\hline yield curve & 0.810 & 0.234 & 0.810 & 0.234 & $1.779 * *$ & 0.444 & $1.779 * *$ & 0.444 \\
\hline wholesale rate volatility & 0.343 & 9.757 & 0.343 & 9.757 & 1.425 & 3.996 & 1.425 & 3.996 \\
\hline bank size & 1.043 & 0.099 & 1.043 & 0.099 & 1.058 & 0.094 & 1.058 & 0.094 \\
\hline herfindahl & 1.075 & 2.257 & 1.075 & 2.257 & 1.499 & 3.179 & 1.499 & 3.179 \\
\hline market share & 0.293 & 0.348 & 0.293 & 0.348 & 0.282 & 0.345 & 0.282 & 0.345 \\
\hline number of markets & $1.020 * * *$ & 0.008 & 1.020 & 0.008 & $1.022 * * *$ & 0.007 & $1.022 * * *$ & 0.007 \\
\hline \# Observations & 4862 & & 4862 & & 4862 & & 4862 & \\
\hline \# failures & 149 & & 149 & & 149 & & 149 & \\
\hline LR Chi(2) & 121.71 & & 121.71 & & 101 & & 101 & \\
\hline
\end{tabular}

\begin{tabular}{|c|c|c|c|c|c|c|c|c|}
\hline & \multicolumn{8}{|c|}{ Negative change hazard } \\
\hline & \multicolumn{4}{|c|}{ wholesale rate $=\mathrm{T}$-Bill 3 month rate } & \multicolumn{4}{|c|}{ wholesale rate=Fed funds rate } \\
\hline & $\begin{array}{c}\text { Hazard } \\
\text { ratio }\end{array}$ & $\begin{array}{r}\text { standard } \\
\text { error }\end{array}$ & $\begin{array}{l}\text { Hazard } \\
\text { ratio }\end{array}$ & $\begin{array}{r}\begin{array}{r}\text { standard } \\
\text { error }\end{array}\end{array}$ & $\begin{array}{r}\text { Hazard } \\
\text { ratio }\end{array}$ & $\begin{array}{r}\text { standard } \\
\text { error }\end{array}$ & $\begin{array}{l}\text { Hazard } \\
\text { ratio }\end{array}$ & $\begin{array}{r}\text { standard } \\
\text { error }\end{array}$ \\
\hline absolute change wholesale rate & 0.025 & 0.072 & 0.166 & 0.267 & $0.000 * *$ & 0.000 & 0.505 & 0.311 \\
\hline dummy for negative change & $0.189 * * *$ & 0.104 & & & $0.150 * * *$ & 0.066 & & \\
\hline negative change $e^{*}$ absolute change & 6.596 & 21.995 & & & $8393.370 * *$ & 33814.140 & & \\
\hline dummy for positive change & & & $5.295 * * *$ & 2.911 & & & $6.654 * * *$ & 2.922 \\
\hline positive change ${ }^{*}$ absolute change & & & 0.152 & 0.506 & & & $0.000 * *$ & 0.000 \\
\hline wholesale rate & 1.013 & 0.264 & 1.013 & 0.264 & $1.819 * * *$ & 0.378 & $1.819 * * *$ & 0.378 \\
\hline yield curve & 0.913 & 0.322 & 0.913 & 0.322 & $1.857^{* *}$ & 0.558 & $1.857^{* *}$ & 0.558 \\
\hline wholesale rate volatility & $1.160 * * *$ & 0.253 & $1.160^{* * *}$ & 2.530 & $1.588 * * *$ & 3.501 & $1.588 * * *$ & 3501.053 \\
\hline bank size & 1.154 & 0.200 & 1.154 & 0.200 & 1.144 & 0.181 & 1.144 & 0.181 \\
\hline herfindahl & 0.732 & 2.318 & 0.732 & 2.318 & 1.094 & 3.523 & 1.094 & 3.523 \\
\hline market share & $0.019 * * *$ & 0.028 & $0.019 * * *$ & 0.028 & $0.012 * * *$ & 0.019 & $0.012 * * *$ & 0.019 \\
\hline number of markets & $1.026 * * *$ & 0.009 & $1.026 * * *$ & 0.009 & $1.026 * * *$ & 0.008 & $1.026 * * *$ & 0.008 \\
\hline \# Observations & 4862 & & 4862 & & 4862 & & 4862 & \\
\hline \# failures & 68 & & 68 & & 68 & & 68 & \\
\hline LR Chi(2) & 199.62 & & 199.61 & & 178.62 & & 178.62 & \\
\hline
\end{tabular}

Note: Semi-parametric estimation of the subhazards of positive and negative retail rate changes based on a sample of spells considering only changes which are not reversed within one week as spell "ends". Hazard ratios higher than unity imply an increased hazard of changing the retail rate. Hazard ratios lower than unity imply a lower probability of changing the retail rate and thus more rigid retail rates. 
Table 10: Competing risks model estimation of the subhazard ratios for positive and negative changes of fixed credit card rate

\begin{tabular}{|c|c|c|c|c|c|c|c|c|}
\hline & \multicolumn{8}{|c|}{ Positive change hazard } \\
\hline & \multicolumn{4}{|c|}{ wholesale rate $=T$-Bill 3 month rate } & \multicolumn{4}{|c|}{ wholesale rate=Fed funds rate } \\
\hline & $\begin{array}{r}\text { Hazard } \\
\text { ratio }\end{array}$ & $\begin{array}{r}\begin{array}{c}\text { standard } \\
\text { error }\end{array} \\
\end{array}$ & $\begin{array}{r}\text { Hazard } \\
\text { ratio }\end{array}$ & $\begin{array}{r}\text { standard } \\
\text { error }\end{array}$ & $\begin{array}{r}\text { Hazard } \\
\text { ratio }\end{array}$ & $\begin{array}{r}\text { standard } \\
\text { error }\end{array}$ & $\begin{array}{r}\text { Hazard } \\
\text { ratio }\end{array}$ & $\begin{array}{r}\text { standard } \\
\text { error }\end{array}$ \\
\hline absolute change wholesale rate & $0.033 * * *$ & 0.024 & $0.015 * * *$ & 0.019 & $0.145^{* * *}$ & 0.089 & $0.346 * * *$ & 0.097 \\
\hline dummy for negative change & $0.519 * *$ & 0.163 & & & $0.465 * * *$ & 0.122 & & \\
\hline negative change ${ }^{*}$ absolute change & 0.464 & 0.677 & & & 1.671 & 1.289 & & \\
\hline dummy for positive change & & & $1.925 * *$ & 0.604 & & & $2.726 * * *$ & 0.711 \\
\hline positive change ${ }^{*}$ absolute change & & & 2.156 & 3.149 & & & $0.001 * * *$ & 0.001 \\
\hline wholesale rate & $1.419 *$ & 0.304 & $1.419 *$ & 0.304 & $1.782 * * *$ & 0.339 & $1.796 * * *$ & 0.340 \\
\hline yield curve & 1.024 & 0.310 & 1.024 & 0.310 & 1.430 & 0.429 & 1.489 & 0.446 \\
\hline wholesale rate volatility & 0.000 & 0.000 & 0.000 & 0.000 & $0.999 * *$ & 0.001 & $0.999 * *$ & 0.001 \\
\hline bank size & 0.939 & 0.108 & 0.939 & 0.108 & 0.896 & 0.108 & 0.898 & 0.106 \\
\hline herfindahl & 0.736 & 1.529 & 0.736 & 1.529 & 1.048 & 1.940 & 1.077 & 2.013 \\
\hline market share & 0.924 & 1.276 & 0.924 & 1.276 & 1.373 & 1.891 & 1.410 & 1.926 \\
\hline number of markets & $1.013 *$ & 0.007 & $1.013 *$ & 0.007 & $1.016 * *$ & 0.007 & $1.015 * *$ & 0.007 \\
\hline \# Observations & 4982 & & 4982 & & 4982 & & 4982 & \\
\hline \# failures & 112 & & 112 & & 112 & & 112 & \\
\hline LR Chi(2) & 131.92 & & 131.93 & & 142.45 & & 172.42 & \\
\hline
\end{tabular}

Negative change hazard

\begin{tabular}{|c|c|c|c|c|c|c|c|c|}
\hline & \multicolumn{8}{|c|}{ Negative change hazard } \\
\hline & \multicolumn{4}{|c|}{ wholesale rate $=$ T-Bill 3 month rate } & \multicolumn{4}{|c|}{ wholesale rate=Fed funds rate } \\
\hline & $\begin{array}{r}\text { Hazard } \\
\text { ratio }\end{array}$ & $\begin{array}{r}\begin{array}{r}\text { standard } \\
\text { error }\end{array}\end{array}$ & $\begin{array}{l}\text { Hazard } \\
\text { ratio }\end{array}$ & $\begin{array}{r}\text { standard } \\
\text { error }\end{array}$ & $\begin{array}{r}\text { Hazard } \\
\text { ratio }\end{array}$ & $\begin{array}{r}\text { standard } \\
\text { error }\end{array}$ & $\begin{array}{r}\text { Hazard } \\
\text { ratio }\end{array}$ & $\begin{array}{r}\text { standard } \\
\text { error }\end{array}$ \\
\hline absolute change wholesale rate & $0.000 * *$ & 0.000 & 0.400 & 0.287 & $0.001 * * *$ & 0.002 & 0.681 & 0.250 \\
\hline dummy for negative change & $0.117^{* * *}$ & 0.051 & & & $0.145 * * *$ & 0.056 & & \\
\hline negative change ${ }^{\star}$ absolute change & $407.952 * *$ & 1597.595 & & & $782.421 * * *$ & 1894.928 & & \\
\hline dummy for positive change & & & 8.535 & 3.703 & & & $7.735 * * *$ & 2.960 \\
\hline positive change ${ }^{\star}$ absolute change & & & 0.000 & 0.001 & & & $0.000 * * *$ & 0.000 \\
\hline wholesale rate & 1.331 & 0.279 & 1.331 & 0.279 & $2.008 * * *$ & 0.365 & $1.880 * * *$ & 0.350 \\
\hline yield curve & 1.046 & 0.324 & 1.046 & 0.324 & $1.745 *$ & 0.538 & $1.715 *$ & 0.532 \\
\hline wholesale rate volatility & $1.210 * * *$ & 2.230 & 1.210 & 2.230 & $1.001 * * *$ & 0.000 & $1.001 * * *$ & 0.000 \\
\hline bank size & 1.059 & 0.117 & 1.059 & 0.117 & 1.029 & 0.118 & 1.024 & 0.118 \\
\hline herfindahl & 0.534 & 1.309 & 0.534 & 1.309 & 0.785 & 1.801 & 0.639 & 1.470 \\
\hline market share & 1.738 & 2.310 & 1.738 & 2.310 & 1.979 & 2.587 & 2.133 & 2.792 \\
\hline number of markets & 0.999 & 0.008 & 0.999 & 0.008 & 1.001 & 0.008 & 1.002 & 0.008 \\
\hline \# Observations & 4982 & & 4982 & & 4982 & & 4982 & \\
\hline \# failures & 80 & & 80 & & 80 & & 80 & \\
\hline LR Chi(2) & 163.17 & & 163.17 & & 127.05 & & 133.33 & \\
\hline
\end{tabular}

Note: Semi-parametric estimation of the subhazards of positive and negative retail rate changes based on a sample of spells considering only changes which are not reversed within one week as spell "ends". Hazard ratios higher than unity imply an increased hazard of changing the retail rate. Hazard ratios lower than unity imply a lower probability of changing the retail rate and thus more rigid retail rates. 
Chart 1: Distribution of checking account rate durations
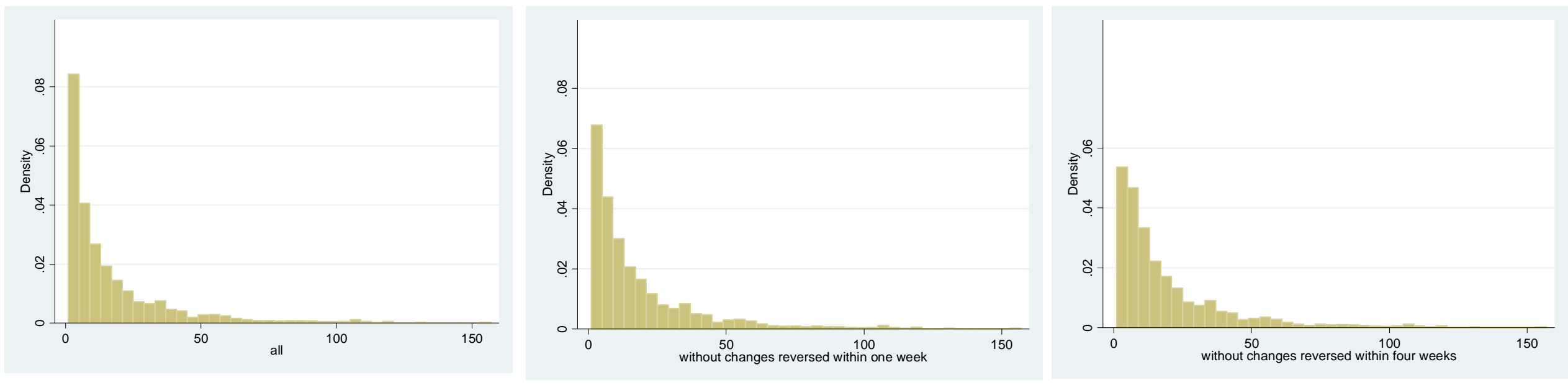

Note: Distribution of the duration of retail rates in weeks. 
Chart 2: Distribution of money market deposit account rate durations
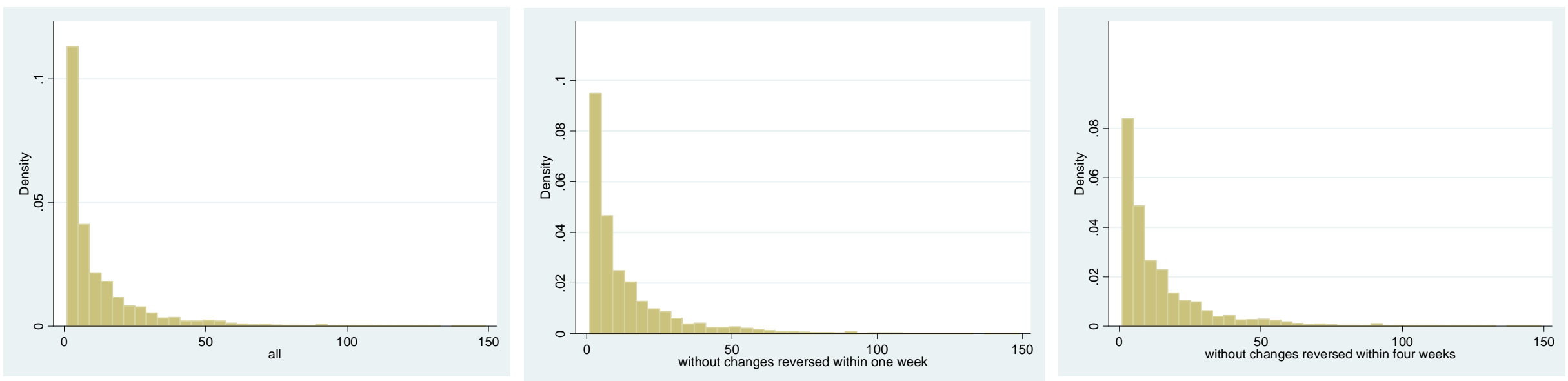

Note: Distribution of the duration of retail rates in weeks. 
Chart 3: Distribution of personal loan rate durations
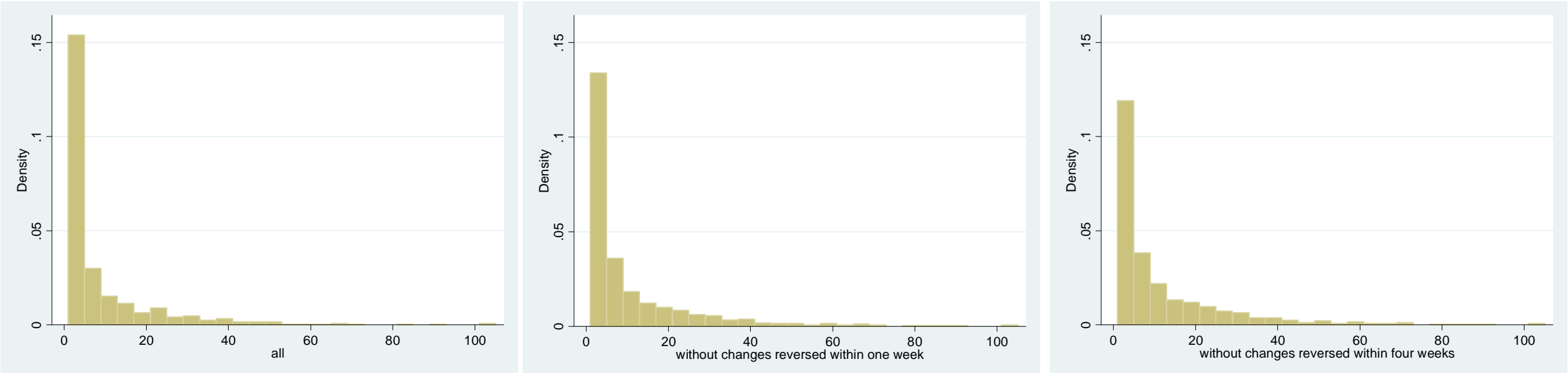

Note: Distribution of the duration of retail rates in weeks. 
Chart 4: Distribution of fixed credit card rate durations
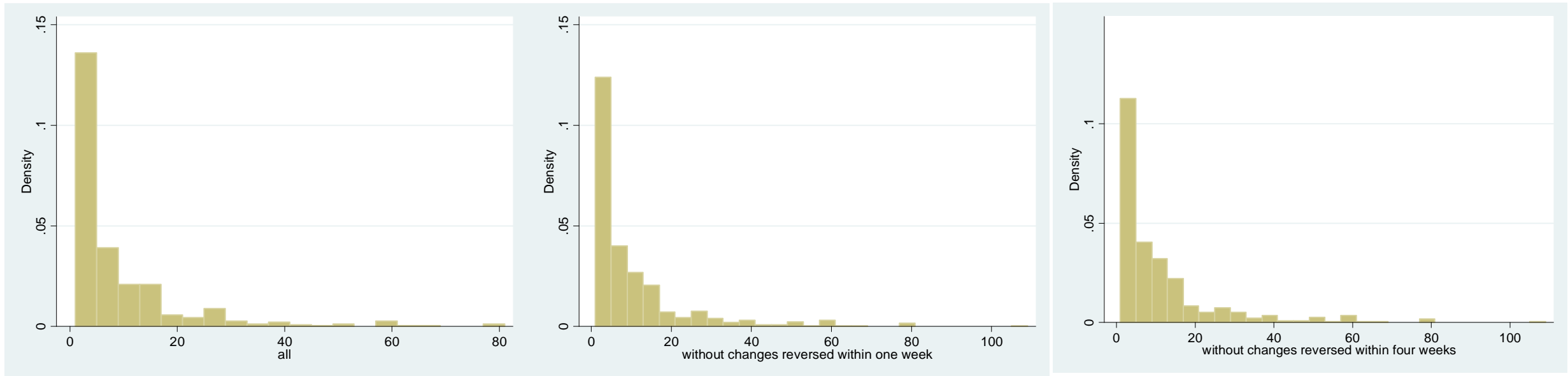

Note: Distribution of the duration of retail rates in weeks. 
Chart 5: Kaplan-Maier hazard function estimates

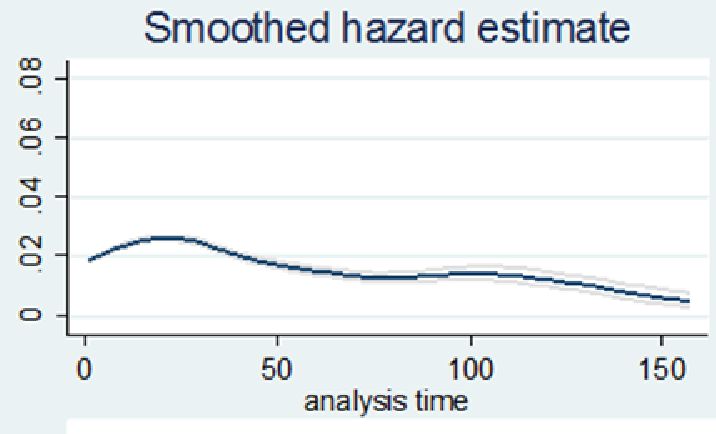

a. Checking account rates

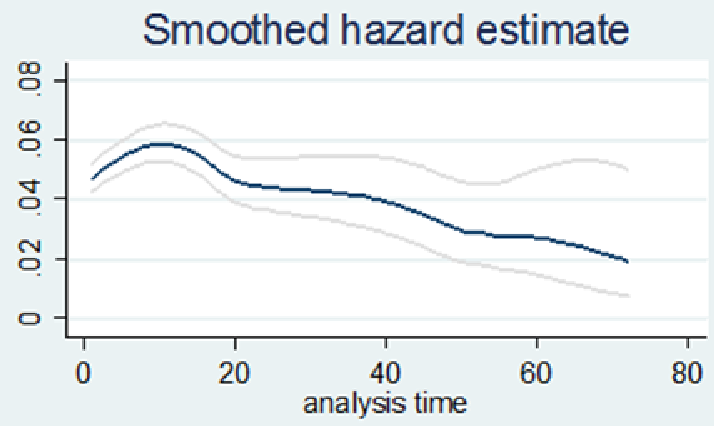

c. Personal loan rates

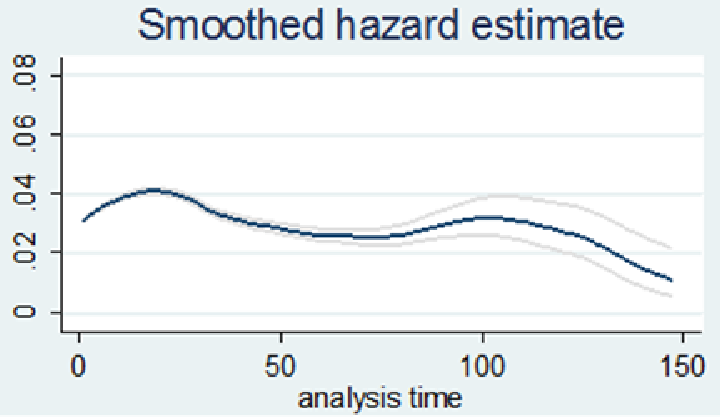

b. Money market deposit account rates

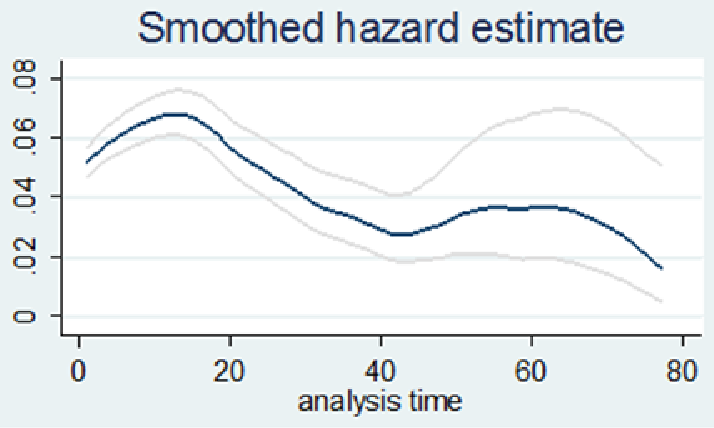

d. Fixed credit card rates

Smoothed hazard

$95 \%$ confidence interval

Note: Nonparametric Kaplan-Maier smoothed hazard estimates based on samples considering only interest rate changes that are not reversed within one week as the ends of spells. 
Chart 6: Baseline hazards
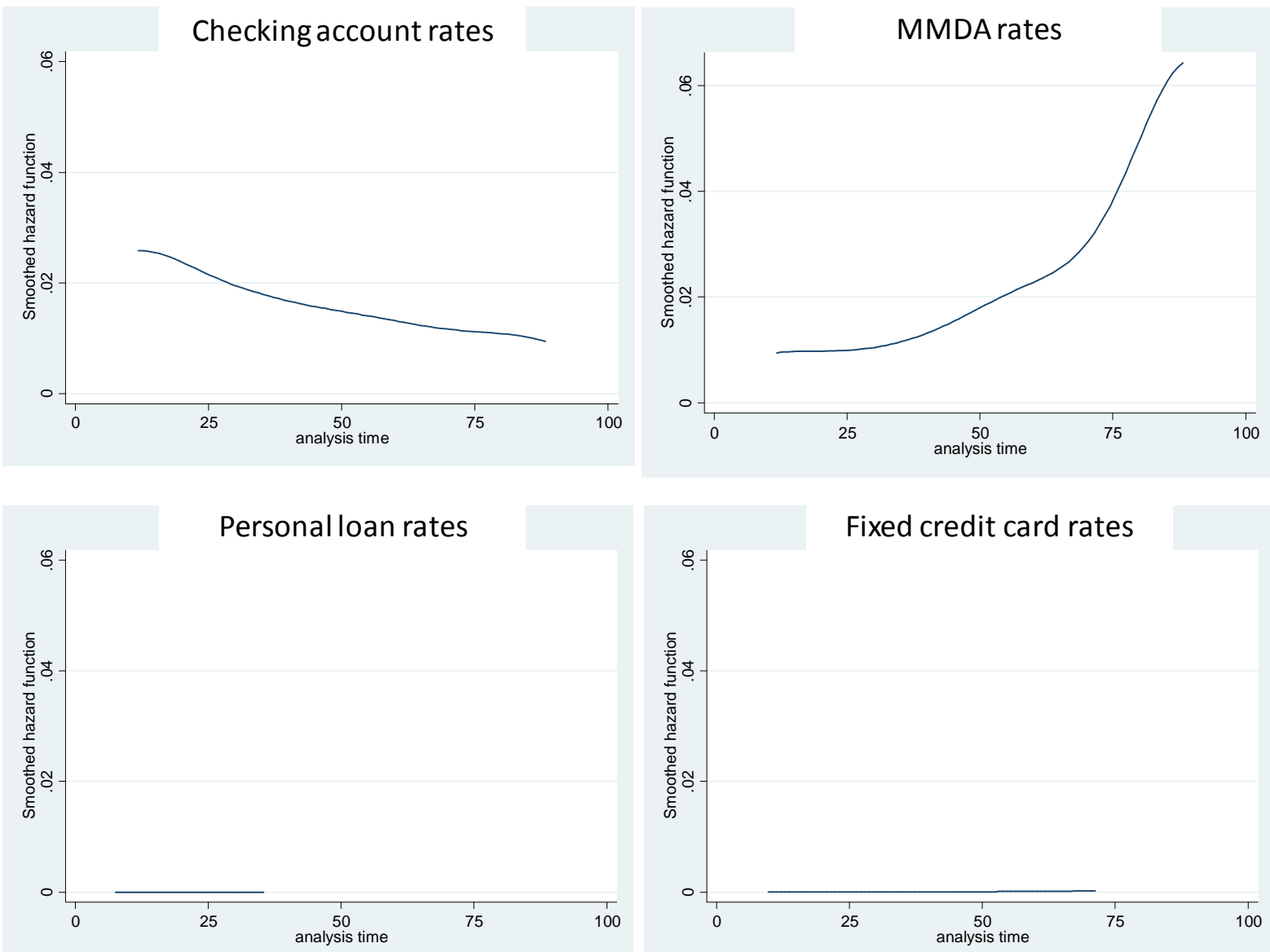

Note: Nonparametric smoothed hazard estimates based on samples at covariates value of zero considering only interest rate changes that are not reversed within one week as the ends of spells. 